\title{
Overexpression of Trypanosoma rangeli trypanothione reductase increases parasite survival under oxidative stress
}

\author{
I. T. BELTRAME-BOTELHO ${ }^{1,2}{ }^{*} \dagger$, P. H. STOCO ${ }^{1} \dagger$, M. STEINDEL ${ }^{1}$, B. ANDERSSON ${ }^{3}$, \\ E. F. PELOSO ${ }^{4}$, F. R. GADELHA ${ }^{4}$ and E. C. GRISARD ${ }^{1} *$ \\ ${ }^{1}$ Departamento de Microbiologia, Imunologia e Parasitologia, Universidade Federal de Santa Catarina, Florianópolis, SC, \\ Brazil \\ ${ }^{2}$ Universidade do Sul de Santa Catarina, Palhoça, SC, Brazil \\ ${ }^{3}$ Department of Cell and Molecular Biology, Karolinska Institutet, Stockholm, Sweden \\ ${ }^{4}$ Departamento de Bioquímica e Biologia Tecidual, Instituto de Biologia, Universidade de Campinas, Campinas, SP, Brazil
}

(Received 25 April 2016; revised 13 September 2016; accepted 16 September 2016)

\section{SUMMARY}

The infectivity and virulence of pathogenic trypanosomatids are directly associated with the efficacy of their antioxidant system. Among the molecules involved in the trypanosomatid response to reactive oxygen or nitrogen species, trypanothione reductase (TRed) is a key enzyme. In this study, we performed a molecular and functional characterization of the TRed enzyme from Trypanosoma rangeli ( $T r$ TRed), an avirulent trypanosome of mammals. The $T r$ TRed gene has an open reading frame (ORF) of $1473 \mathrm{bp}(\sim 490 \mathrm{aa}, 53 \mathrm{kDa})$ and occurs as a single-copy gene in the haploid genome. The predicted protein contains two oxidoreductase domains, which are equally expressed in the cytosol of epimastigotes and trypomastigotes. Nicotinamide adenine dinucleotide phosphate (NADPH) generation is reduced and endogenous $\mathrm{H}_{2} \mathrm{O}_{2}$ production is elevated in $T$. rangeli Choachí strain compared with $T$. cruzi $\mathrm{Y}$ strain epimastigotes. Oxidative stress induced by $\mathrm{H}_{2} \mathrm{O}_{2}$ does not induce significant alterations in $\operatorname{Tr}$ TRed expression. Overexpression of $\operatorname{Tr} \mathrm{TRed}$ did not influence in vitro growth or differentiation into trypomastigotes, but mutant parasites showed increased resistance to $\mathrm{H}_{2} \mathrm{O}_{2}$-induced stress. Our results indicate that T. rangeli constitutively expresses TRed during the entire life cycle, with reduced levels during infective and non-replicative trypomastigote stages.

Key words: Trypanosoma rangeli, Trypanothione reductase, antioxidant defence.

\section{INTRODUCTION}

During infection of the mammalian host, trypanosomatids are exposed to a variety of oxidizing environments. The reduced form of the thiol trypanothione, which is unique to trypanosomatids, is thought to play a central role in the redox defence systems of these parasites to such stresses (Flohé, 2012; Peloso et al. 2012; Paiva and Bozza, 2014). This reduced form is generated by the action of trypanothione reductase (TRed), an enzyme belonging to the flavoprotein disulphide oxidoreductase family. The substrate of this enzyme is trypanothione disulphide. TRed is a specific NADPH-dependant homodimeric protein that requires flavin-adenine dinucleotide (FAD) as a coenzyme and a redox-active cysteine disulphide in the active site (Fairlamb and Cerami, 1992). TRed and peroxidases play a role in protecting these parasites against oxidative stress that may arise internally as a result of their aerobic metabolism and externally by the action of the host immune response (Fairlamb et al. 1985; Shames et al. 1986).

* Corresponding authors: Departamento de Microbiologia, Imunologia e Parasitologia, Universidade Federal de Santa Catarina, Florianópolis, SC, 88040970, Brazil. E-mail: ingridthaisbb@hotmail.com, edmundo.grisard@ufsc.br

$\dagger$ These authors have equally contributed to this work.
Among the trypanosomatids that are trypanothionedependent organisms, Trypanosoma rangeli is a nonvirulent protozoan parasite of mammals that is genomically related to Trypanosoma cruzi, the aetiologic agent of Chagas disease (Guhl and Vallejo, 2003; Stoco et al. 2014). Compared with T. cruzi, T. rangeli possesses striking new genomic features such as (1) considerably less amplification of the gene copy number within multigene virulence factor families, such as mucin-associated proteins (MASPs), trans-sialidases and mucins; (2) the presence of vestigial orthologues of the interference RNA (RNAi) machinery, which are insufficient to constitute a functional pathway; and (3) a reduced repertoire of genes encoding antioxidant defence enzymes (Stoco et al. 2014). These parasites also occur in sympatry in a wide overlapping area in South and Central America, infecting triatomine bugs, humans and a variety of sylvatic and domestic mammals (Coura et al. 1996; Grisard et al. 1999; Guhl and Vallejo, 2003). Moreover, T. rangeli and T. cruzi can share at least $60 \%$ of their soluble antigenic constitution, which can lead to a false-positive diagnosis of chagasic infection in people carrying $T$. rangeli, with consequent socio-economic effects (Azambuja et al. 2005; Ferreira et al. 2010).

Trypanosoma cruzi and Trypanosoma brucei express high levels of TRed (Piacenza et al. 2009b), supporting its essential role in parasite viability.

Parasitology Open (2016), Vol. 2, e18; page 1 of 14. (C) Cambridge University Press 2016. This is an Open Access article, distributed under the terms of the Creative Commons Attribution licence (http://creativecommons.org/licenses/by/4.0/), which permits unrestricted re-use, distribution, and reproduction in any medium, provided the original work is properly cited. 
Trypanosoma brucei parasites became more susceptible to $\mathrm{H}_{2} \mathrm{O}_{2}$-induced oxidative stress and were avirulent only when TRed levels were reduced to $<10 \%$ (Krieger et al. 2000). Interestingly, TRed levels were not increased in T. cruzi during metacyclogenesis (Piacenza et al. 2009a, b).

Little is known regarding the behaviour of $T$. rangeli in response to oxidative stress or the relevance of TRed to survival and adaptation in response to the new environments encountered by the parasite during its life cycle. Thus, in the present study, we characterized the $T$. rangeli TRed gene and its expression levels during the parasite life cycle and under oxidative stress conditions. The relevance of this enzyme for the parasite response to reactive oxygen species (ROS) is highlighted.

\section{MATERIALS AND METHODS}

\section{Parasites}

Trypanosoma rangeli (Choachí strain) and T. cruzi (Y strain) epimastigotes were maintained at $27 \cdot 5{ }^{\circ} \mathrm{C}$ in liver infusion tryptose medium (LIT) supplemented with $10 \%$ heat-inactivated fetal bovine serum (FBS), 100 units $\mathrm{mL}^{-1}$ penicillin and 100 $\mu \mathrm{g} \mathrm{mL}^{-1}$ streptomycin by weekly passages after cyclic mouse-triatomine-mouse passages. Polymerase chain reaction (PCR) showed that all samples tested negative for the presence of Mycoplasma sp. For DNA or protein extraction and for in vitro oxidative stress experiments, epimastigotes in the exponential growth phase were harvested during the late $\log$ phase and washed twice with sterile PBS (pH 7.2). Trypanosoma rangeli trypomastigotes were obtained in vitro using previously described conditions (Koerich et al. 2002). Trypanosoma cruzi culturederived trypomastigotes (TCT) were obtained by infection of Vero cells as previously described (EgerMangrich et al. 2001).

\section{Isolation of DNA and RNA}

Total RNA was extracted from $T$. rangeli epimastigotes using the TRIzol method (Invitrogen) and then treated with DNase I, according to the manufacturer's instructions. Trypanosoma rangeli and $T$. cruzi genomic DNA (gDNA) was isolated using a standard phenol-chloroform method (Sambrook et al. 2001). The purity and quality of the obtained DNA and RNA were assessed spectrophotometrically and via agarose gel electrophoresis.

\section{Protein extraction}

Epimastigote or trypomastigote forms were washed once with PBS ( $\mathrm{pH} 7 \cdot 2$ ), lysed by repeated pipetting in ice-cold lysis buffer $(0 \cdot 25 \mathrm{M}$ sucrose, $0 \cdot 25 \%$ Triton $\mathrm{X}-100, \quad 10 \mathrm{~mm}$ EDTA) containing a protease inhibitor cocktail (2 mM 4-(2-aminoethyl)benzenesulfonyl fluoride hydrochloride, $0 \cdot 3 \mu \mathrm{M}$ aprotinin, $116 \mu \mathrm{m}$ bestatin, $14 \mu \mathrm{M}$ E-64, $1 \mu \mathrm{M}$ leupeptin and 1 тм EDTA) (Sigma-Aldrich). Cellular debris were removed by centrifugation at $12000 \mathrm{~g}$ for $20 \mathrm{~min}$ at $4{ }^{\circ} \mathrm{C}$ (Romero et al. 2014). The protein concentration was determined by the Bradford method (BioRad) using BSA as a standard (Bradford, 1976). Parasite extracts were stored at $-20^{\circ} \mathrm{C}$ until use.

\section{$c D N A$ Synthesis and $q P C R$}

For first-strand cDNA synthesis, $1 \mu \mathrm{g}$ of total RNA was used in a $20-\mu \mathrm{L}$ final reaction volume containing 200 U Moloney Murine Leukaemia Virus Reverse Transcriptase (M-MLV RT), 1X First Strand Buffer, $200 \mu \mathrm{M}$ dNTP, 10 pmoles oligodT-Anchor, $10 \mathrm{~mm}$ dithiothreitol (DTT), $40 \mathrm{U}$ RNaseOUT $^{\mathrm{TM}}$ (Invitrogen). The mixture was incubated at $37^{\circ} \mathrm{C}$ for $50 \mathrm{~min}$, heat-inactivated at $70^{\circ} \mathrm{C}$ for $15 \mathrm{~min}$ and then diluted 5 -fold in nuclease-free water. The diluted cDNA was used for qPCR amplification on ABI Prism ${ }^{\circledR} 7900$ HT Sequence Detection System (Applied Biosystems) equipment using specific primers (qTRed $T r$-F: 5'-CGA AAG ACT GAT CAC ACC CG-3' and qTRed $T r$-R: 5'- CGA GTG CCG TCT TCT CTA TTC CTC-3'). GAPDH (GenBank AUPL01004827) (GAPDH-F: 5'-GCG ACA CCA GCA TCA AAG AG-3' GAPDH-R: 5'- CTG TGC TCA CAA GTT CCT CG-3') and RNA60S (GenBank AUPL01005494) (RNA60S-F: 5'-CGA TGA AGC TCA AGT GGA CC-3'/RNA60S-R: 5'CGG TTG TAC TTG ACG GGA AC-3') genes were used as references, and a negative control containing no cDNA was included in each reaction set. Reactions consisted of $0.3 \mu \mathrm{M}$ of each q $T r$ TRed

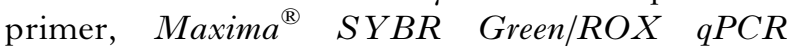
Master Mix reagent (Thermo Scientific), $2 \mu \mathrm{L}$ template cDNA and nuclease-free water up to $10 \mu \mathrm{L}$. The temperature profile for all reactions was $95{ }^{\circ} \mathrm{C}$ for $10 \mathrm{~min}$, followed by 40 cycles of denaturation $\left(95^{\circ} \mathrm{C}\right.$ for $\left.15 \mathrm{~s}\right)$ and annealing/extension $\left(61{ }^{\circ} \mathrm{C}\right.$ for $1 \mathrm{~min})$. A final step was included to obtain the dissociation curve $\left(95^{\circ} \mathrm{C}, 60^{\circ} \mathrm{C}\right.$ and $95^{\circ} \mathrm{C}$ for $15 \mathrm{~s}$ each). The reaction efficiency for each primer set was calculated after a 5-point serial dilution (1:2) of cDNA pools and gDNA. All qPCR assays were performed using biological and technical triplicates. Raw quantification cycle $\left(C_{\mathrm{q}}\right)$ results were obtained using SDS 2.4 data analysis software (Applied Biosystems) and normalized to the geometrical average value of two reference genes for each sample. The amplification efficiency was obtained with the $E=10\left(-1\right.$ slope $\left.^{-1}\right)$ formula (Pfaffl, 2001). The relative quantification method (Livak and Schmittgen, 2001) was used to assess variations in transcript levels. Comparison of transcript levels between two samples was conducted using the 
unpaired Student's $t$-test with Prism $5 \cdot 0$ (GraphPad) and $P<0 \cdot 05$.

\section{Identification and Cloning of T. rangeli TRed ( $T r T R e d)$}

Using the T. cruzi TRed gene as the query (GenBank Accession Number CAA78360), the complete sequence of the $\operatorname{Tr}$ TRed gene was retrieved via Blast from $T$. rangeli genomic and transcriptomic sequences available in GenBank and TriTrypDB (www.tritrypdb.org) (Aslett et al. 2010), as well as from sequences recently generated using the Illumina platform at the Science for Life Laboratory, Karolinska Institutet, Sweden. The entire $\operatorname{Tr}$ TRed open reading frame (ORF) was PCR-amplified using primers $T r$ TRed $B g l$ II $\quad 5^{\prime}$ AGA TCT ATG AAA GCC TTT GAT TTG GTT G-3') and $T r$ TRed $K p n$ I (5'- GGT ACC AGC CTC TAG AGC CGT TTC CG-3'), containing the respective restriction enzyme sites to allow downstream cloning. PCR assays were performed on a Mastercycler ${ }^{\circledR}$ Gradient (Eppendorf) thermocycler using 35 cycles of the following thermal profile for denaturation $\left(95^{\circ} \mathrm{C}, 1 \mathrm{~min}\right)$, annealing $\left(64^{\circ} \mathrm{C}, 1\right.$ min) and extension $\left(72^{\circ} \mathrm{C}, 1 \mathrm{~min}\right)$, including a final extension step at $72{ }^{\circ} \mathrm{C}$ for $5 \mathrm{~min}$. The PCR product was cloned into pGEM-T-Easy vector (Promega), and the resulting constructs were verified by sequencing on an Abi3500 automated DNA sequencer (Life Technologies) using the BigDYE $3 \cdot 1$ kit (Life Technologies) according to the manufacturer's instructions. Both DNA strands were sequenced for each obtained clone, and those presenting a high quality (Phred $\geq 20$ ), as indicated by the Phred/ Phrap/Consed package (Ewing et al. 1998), were clustered and compared with the public databases using the BLAST algorithm (Altschul et al. 1990).

\section{Comparative analysis of TRed expression by \\ $\mathrm{T}$. rangeli and $\mathrm{T}$. cruzi}

Soluble protein extracts $(50 \mu \mathrm{g})$ of different life cycle stages of $T$. rangeli and T. cruzi were resolved by sodium dodecyl sulphate- $12 \%$ polyacrylamide gel electrophoresis (SDS- 12\% PAGE) and electroblotted onto nitrocellulose membranes (GE Healthcare) using an appropriate buffer $(25 \mathrm{~mm}$ Tris; 192 mu glycine; 20\% v/v methanol, $\mathrm{pH} 8 \cdot 3$ ). After blocking with $5 \%$ non-fat milk in blotting buffer $(25 \mathrm{~mm}$ Tris- $\mathrm{HCl}$ pH 7.4, $150 \mathrm{~mm} \mathrm{NaCl}$, and $0 \cdot 1 \%$ Tween-20) overnight at $4{ }^{\circ} \mathrm{C}$ (Gallagher et al. 2008), the membranes were incubated for $1 \mathrm{~h}$ with an anti-rTcTRed mouse polyclonal antiserum (1:500) (kindly provided by Dr. Silvane Murta CPqRR/Fiocruz) or anti $\alpha$-tubulin monoclonal antibody (Cell Signaling Technology) (1:1000) as a loading control. Detection of expressed TRed was conducted using anti-mouse $\operatorname{IgG}$ conjugated to horseradish peroxidase (HRP) (1:10000), followed by the enhanced chemiluminescence (ECL) kit (Pierce) according to the manufacturer's recommendations. The Western blots were digitally recorded and analysed using the Image $1.463 \mathrm{r}$ software package. The relative protein expression was determined by the ratio of the TRed and $\alpha$-tubulin band intensities.

\section{Assessment of the enzymatic activity of $\mathrm{T}$. rangeli TRed}

The $T r$ TRed activity was assessed spectrophotometrically by measuring nicotinamide adenine dinucleotide phosphate (NADPH) oxidation at 340 $\mathrm{nm}$ as formerly described (Jockers-Scherübl et al. 1989). Kinetic assays were conducted in 96-well microplates at $27^{\circ} \mathrm{C}$ in an incubation medium containing $20 \mathrm{~mm}$ HEPES $\mathrm{pH} 7 \cdot 4,30 \mathrm{~mm} \mathrm{NaCl}, 0 \cdot 1$ mM EDTA, $150 \mu \mathrm{M} \mathrm{NADPH,} 50 \mu \mathrm{M} \mathrm{T}(\mathrm{S})_{2}$ and 1.5 $\mu \mathrm{g} \mu \mathrm{L}^{-1}$ of soluble $T$. rangeli epimastigote protein extract in a final volume of $200 \mu \mathrm{L}$. The reaction was started by the addition of trypanothione disulphide $\left(\mathrm{T}(\mathrm{S})_{2}\right)$ and followed for $3 \mathrm{~min}$. A negative (no substrate) and positive control $\left(0 \cdot 1 \mu \mathrm{g} \mu \mathrm{L}^{-1}\right.$ of $\mathrm{r} T c$ Tred) were included in each enzymatic assay. One unit of TRed activity was defined as the amount of enzyme required to oxidize $1 \mu \mathrm{M}$ of $\mathrm{NADPH}$ to $\mathrm{NADP}^{+}$per minute at $27^{\circ} \mathrm{C}$. The results were expressed as $\mu \mathrm{M} \mathrm{min}^{-1} \mathrm{mg}$ of protein $^{-1}$. The reference values used were an NADPH molar extinction coefficient $\varepsilon M=6220$ $\mathrm{M}^{-1} \mathrm{~cm}^{-1}$ and assuming a $1-\mathrm{cm}$ path length.

\section{Oxidative stress induced by $\mathrm{H}_{2} \mathrm{O}_{2}$ in T. rangeli}

Exponential growth phase epimastigotes $\left(5 \times 10^{7}\right.$ cells) were harvested by centrifugation $(3000 \boldsymbol{g}$ for $10 \mathrm{~min}$ ) and washed twice in sterile PBS $\mathrm{pH} 7 \cdot 2$. The parasites were then resuspended in LIT medium supplemented with $10 \% \mathrm{FBS}$ and incubated in the presence of $67 \mu \mathrm{M} \mathrm{H} \mathrm{H}_{2} \mathrm{O}_{2}$ for 30,60 or $90 \mathrm{~min}$ at $27^{\circ} \mathrm{C}$. The $\mathrm{IC}_{50}$ was determined as previously described (Romero et al. 2014). Considering that such a concentration of $\mathrm{H}_{2} \mathrm{O}_{2}$ in a single dose could induce bias in an in vitro system, the parasites were exposed to increasing concentrations of $\mathrm{H}_{2} \mathrm{O}_{2}$ every $20 \mathrm{~min}$ up to $1 \mathrm{~h}$ while another sample received no $\mathrm{H}_{2} \mathrm{O}_{2}$ (negative control). After incubation, the parasites were centrifuged $(3000 \boldsymbol{g}$ for $10 \mathrm{~min})$ and washed twice with PBS ( $\mathrm{pH} 7 \cdot 4$ ), and the pellet was stored at $-20{ }^{\circ} \mathrm{C}$ for protein extraction. TRed expression and activity were measured as described above.

\section{Detection of intracellular ROS in T. rangeli epimastigotes}

The presence of intracellular ROS in $T$. rangeli and T. cruzi epimastigotes was assessed using the 
$2^{\prime}-7^{\prime}$-dichlorodihydrofluorescene diacetate (DCFHDA) probe (Sigma-Aldrich) as previously described (Wang and Joseph, 1999). Briefly, $5 \times 10^{5}$ parasites well $^{-1}(200 \mu \mathrm{L})$ were incubated in LIT medium supplemented with $10 \%$ heat-inactivated $\mathrm{FBS}$ in the presence of different $\mathrm{H}_{2} \mathrm{O}_{2}$ concentrations (0-1 $\mathrm{mm}$ ) in black 96 -well plates. After $10 \mathrm{~min}, 10 \mu \mathrm{m}$ of DCFH-DA well ${ }^{-1}$ was added, and the fluorescence intensity was determined in a TECAN Infinite M200 spectrofluorometer (Switzerland) for $1 \mathrm{~h}$ using an excitation wavelength of $485 \mathrm{~nm}$ and an emission wavelength of $535 \mathrm{~nm}$. Untreated parasites (no $\mathrm{H}_{2} \mathrm{O}_{2}$ ) and $10 \mu \mathrm{M}$ of DCFH-DA probe in lysis buffer were used as negative controls. Two independent experiments were performed in quadruplicate. The results are expressed as relative fluorescence units that are directly proportional to the increase in the ROS concentration over the time course.

\section{NADPH production through the measurement of glucose-6-phosphate dehydrogenase (G6PD) and 6- phosphogluconate dehydrogenase (6PGD) activities}

NADPH production was determined as previously described (Mielniczki-Pereira et al. 2007). Briefly, cells were collected by centrifugation and resuspended in PBS pH 7.2 in the presence of a protease inhibitor cocktail (Cocktail Set III, Calbiochem, Catalogue \#: 539134). The combined activities of G6PD and 6PGD were measured by $\mathrm{NADP}^{+}$reduction at $340 \mathrm{~nm}$ after the addition of parasites $\left(5 \times 10^{7}\right.$ cells $\left.\mathrm{mL}^{-1}\right)$ to the reaction mixture $(50 \mathrm{~mm}$ Tris$\mathrm{HCl}, \mathrm{pH} 7 \cdot 6,50 \mathrm{~mm} \mathrm{KCl}, 0 \cdot 1 \%$ Triton $\mathrm{X}-100$, $250 \mu \mathrm{M} \mathrm{NADP}+, 2 \mathrm{~mm} \mathrm{MgCl}_{2}, 1 \mathrm{~mm}$ 6-phosphogluconate and $1 \mathrm{~mm}$ glucose-6-phosphate). 6PGD activity was assessed in the same medium but in the absence of glucose-6-phosphate.

\section{Determination of hydrogen peroxide release}

$\mathrm{H}_{2} \mathrm{O}_{2}$ release by $T$. rangeli epimastigotes was determined as previously described (Peloso et al. 2011). Briefly, $10^{8}$ cells $\mathrm{mL}^{-1}$ were incubated in PBS $\mathrm{pH}$ $7 \cdot 21 \mathrm{~mm}^{-1} \mathrm{MgCl}_{2}$ in the presence of $5 \mathrm{~mm}$ succinate, $60 \mu \mathrm{M}$ digitonin, $1 \mathrm{U} \mathrm{mL}^{-1}$ of HRP and $25 \mu \mathrm{M}$ Amplex Red (Molecular Probes). The fluorescence was monitored at excitation and emission wavelengths of $563 \mathrm{~nm}$ and $587 \mathrm{~nm}$, respectively, using a Hitachi F2500 fluorescence spectrophotometer with continuous stirring. The quantitative correlation between the fluorescence and $\mathrm{H}_{2} \mathrm{O}_{2}$ release by the cells was determined as previously described (Barros et al. 2004).

Effect of antioxidants on the growth of $\mathrm{T}$. rangeli and TRed expression

Epimastigotes $\left(2 \times 10^{6} \mathrm{~mL}^{-1}\right)$ were grown in LIT medium $(10 \% \mathrm{FBS})$ for 15 days at $27^{\circ} \mathrm{C}$ in the presence of reduced glutathione (GSH) or N-acetylcysteine (NAC) (Sigma-Aldrich) at two different concentrations ( 1 and $2.5 \mathrm{~mm}$ ). The experiments were performed in triplicate, and the parasites were counted every day in a Neubauer chamber. Samples were collected on days 1, 3, 5, 7, 9 and 11 to analyse TRed expression by Western blotting using anti-rTcTRed and anti $\alpha$-tubulin antibodies.

\section{Overexpression of TRed in $\mathrm{T}$. rangeli}

The $\operatorname{Tr}$ TRed gene was excised from the pGEM-TEasy vector using $B g l \mathrm{II} / K p n \mathrm{I}$ restriction enzymes and then subcloned into the pLEXSY-NEO2 vector (Jena). All constructs were checked for their restriction profiles and sequenced prior to transfection into $T$. rangeli epimastigotes by electroporation using e Nucleofector ${ }^{\circledR}$ device (Lonza). Briefly, $5 \times$ $10^{6}$ epimastigotes in the $\log$ growth phase were washed twice in PBS (pH 7.2), mixed with $100 \mu \mathrm{L}$ of human $\mathrm{T}$ cell Nucleofector buffer (Lonza) and $10 \mu \mathrm{g}$ of pLEXSY-NEO2 $-\operatorname{Tr}$ TRed construct DNA and transfected using program U-033. After transfection, the parasites were transferred to Neal, Novy, Nicolle-LIT medium and grown at $27.5{ }^{\circ} \mathrm{C}$ for $48 \mathrm{~h}$. The transfectants were then selected via incremental exposure to geneticin (Gibco), from $25 \mu \mathrm{g}$ $\mathrm{mL}^{-1}$ up to a final concentration of $300 \mu \mathrm{g} \mathrm{mL} \mathrm{m}^{-1}$. Parasites transfected with empty vector were generated and compared with wild-type parasites in terms of growth and TRed expression levels. Overexpression of $\operatorname{Tr}$ TRed ( $T$ rTRed + ) by transfected parasites was assessed by Western blotting using an anti-His6-tagged antibody $(1: 200)$ (Santa Cruz Biotechnology). After confirmation, the $\operatorname{Tr}$ TRed+ parasites were harvested during the exponential and late $\log$ phases for protein extraction and for the in vitro oxidative susceptibility assay as described above, using non-transfected wild-type (WT) parasites as a control. Additionally, WT and $\operatorname{Tr}$ TRed+-overexpressing parasites were comparatively evaluated according to their in vitro growth curve and differentiation into trypomastigote forms.

\section{Cytolocalization of the $r$ TrTRed expression sites}

The expression sites of $\operatorname{Tr}$ TRed + by $T$. rangeli were assessed by indirect immunofluorescence assays (IFA). Exponential growth phase WT and $T r$ TRed+ epimastigotes were harvested from LIT by centrifugation $(3000 \mathrm{~g}, 10 \mathrm{~min})$, washed twice with PBS pH 7.2 and adhered onto 13-mm circular glass coverslips for $20 \mathrm{~min}$. The parasites were fixed with $4 \%$ paraformaldehyde $(w / v)$ in PBS and then permeabilized with $0 \cdot 1 \%$ NP-40 or $0 \cdot 1 \%$ Triton X-100. The cells were then blocked with $2 \%$ BSA diluted in PBS and probed with antiHis6-tagged antibody diluted 1:100 in blocking solution. After $90 \mathrm{~min}$, the slides were washed 
extensively with PBS and then incubated for $1 \mathrm{~h}$ with Alexa Fluor 488-conjugated goat-anti-mouse IgG diluted 1:10000 in blocking solution. After washing $3 \times$ with PBS, the parasites were stained for 5 min with $1 \mu \mathrm{g} \mathrm{mL}{ }^{-1}$ of DAPI (4,6-diamidino2 -phenylindole), and the coverslips were mounted over microscopy slides using Hydromount (National Diagnostics). Images were obtained using an Olympus Bx40-FL fluorescence microscope (Olympus).

\section{Susceptibility of TRed-overexpressing T. rangeli epimastigotes to oxidative stress}

The susceptibility of $T$. rangeli-overexpressing $\operatorname{Tr}$ TRed to oxidative stress was compared with that of W'T cells using Alamar Blue (AB) assays as previously described (Räz et al. 1997; Decuypere et al. 2012). Briefly, $5 \times 10^{5} T$. rangeli and T. cruzi epimastigotes were exposed to hydrogen peroxide (Sigma-Aldrich) prepared at different dilutions (0$1 \mathrm{mM}$ ) and incubated for $48 \mathrm{~h}$ at $26^{\circ} \mathrm{C}$ in quadruplicate in 96-well plates. After incubation for $24 \mathrm{~h}, 20$ $\mu \mathrm{L}$ of $\mathrm{AB}$ reagent (Invitrogen) was added to each well to assess the parasite viability via fluorescence emission at $600 \mathrm{~nm}$. Data from treated and nontreated cultures were used to calculate the $\mathrm{IC}_{50}$ by a sigmoidal regression analysis (with a variable slope) using GraphPad Prism v.5.0. Untreated control parasites and reagent blanks were included in each test plate.

\section{In vitro interaction of THP-1 cells and $\mathrm{T}$. rangeli overexpressing $\mathrm{Tr}$ TRed}

Cells of the human acute monocytic leukaemia cell line THP-1 (ATCC\#TIB-202) were cultured at $37{ }^{\circ} \mathrm{C}$ in a $5 \% \mathrm{CO}_{2}$ atmosphere using RPMI 1640 medium (HiMedia Laboratories) supplemented with $1 \%$ glutamine, $10 \%$ heat-inactivated FBS, $12.5 \mathrm{~mm}$ HEPES (Gibco), $100 \mathrm{U} \mathrm{mL}^{-1}$ penicillin, $100 \mu \mathrm{g} \mathrm{mL}^{-1} \quad$ streptomycin (Gibco), $2 \mathrm{mM}$ Glutamax $^{\circledR}$ (Gibco) and $1 \mathrm{~mm}$ sodium pyruvate (Gibco). Monocytes were harvested during the logarithmic growth phase and transferred to medium containing $50 \mu \mathrm{g} \mathrm{mL}^{-1}$ phorbol myristate acetate (Sigma-Aldrich) to induce adherence and differentiation of the macrophages (Schwende et al. 1996). Prior to the in vitro infection assays with $T$. rangeli, a total of $1 \times 10^{5}$ macrophages were seeded onto 13-mm circular glass coverslips placed in 6well plates and then incubated for $72 \mathrm{~h}$ at $37^{\circ} \mathrm{C}$ in a $5 \% \mathrm{CO}_{2}$ atmosphere (Romero et al. 2005). After removal of non-adherent cells by washing the plate wells twice with sterile PBS ( $\mathrm{pH} \mathrm{7 \cdot 2),} \mathrm{THP-1-}$ derived macrophages were incubated with $T$. rangeli trypomastigotes overexpressing $T r$ TRed for $1 \mathrm{~h}$ at $37^{\circ} \mathrm{C}$ in a $5 \% \mathrm{CO}_{2}$ atmosphere using a parasite-to-cell ratio of $25: 1$. Non-adherent parasites were removed by washing with PBS, which was considered the initial time point of infection (T0), and the progression of the parasite-cell interaction was observed at 2 (T2), 4 (T4), 6 (T6) and 24 hours (T24) after infection. The cells were then stained with Giemsa, mounted on microscope slides with Entellan $^{\circledR}$ (Merck) and observed by light microscopy. The number of infected cells was determined by counting 200 randomly chosen cells per coverslip for each of the time points, strains and species. The assays were performed using biological triplicate samples and non-infected cells were used as controls.

\section{Statistical analyses}

All experiments were performed in triplicate, and the results are presented as the mean and standard deviation (S.D.M.) or standard error of the mean (s.E.M.). Significant differences were assessed by one-way analysis of variance (ANOVA) followed by the Bonferroni post-hoc test or Student's $t$-test using GraphPad Prism v.5.0 software as indicated in the figure legends.

\section{RESULTS}

In silico analysis revealed that the $T$. rangeli TRed gene ( $T r$ TRed) has an ORF of $1473 \mathrm{nt}$ encoding a predicted protein of 491 aa $(\sim 53 \cdot 5 \mathrm{kDa})$ with a predicted isoelectric point of 6.33. $\operatorname{Tr}$ TRed is present as a single copy in the parasite genome and displays conserved catalytic domains, particularly the disulphide-binding site, FAD and NADH binding domains among different kinetoplastid species (Fig. 1).

Assessment of the intracellular localization of $T r$ TRed in $T$. rangeli epimastigotes overexpressing the enzyme by IFA revealed dispersed fluorescence throughout the parasite cytoplasm, suggesting a cytosolic localization (Fig. 2), which is consistent with the in silico prediction for the native protein.

The relative abundance of the $T r$ TRed protein assessed by Western blotting in $T$. rangeli epimastigotes and trypomastigotes revealed no significant differences (Fig. 3A). The absence of TRed stagespecific expression was also observed for the homologous protein in T. cruzi (Tc'TRed).

Trypanosoma rangeli $\mathrm{TRed}$ was active in both epimastigotes and trypomastigotes $(3.11$ and $1.82 \mu \mathrm{M}$ $\min ^{-1} \mathrm{mg}$ of protein $^{-1}$, respectively), suggesting that its activity is significantly increased in the replicative parasite forms (Fig. 3B). Interestingly, $T$. cruzi TRed was more active in trypomastigotes than in epimastigotes $\left(2.74\right.$ and $1.71 \mu \mathrm{M} \mathrm{min}{ }^{-1} \mathrm{mg}$ of protein ${ }^{-1}$, respectively), but no significant differences were observed between the infective and replicative forms of the parasite. Considering this difference, we also comparatively assessed the TrTREd mRNA levels between replicating 


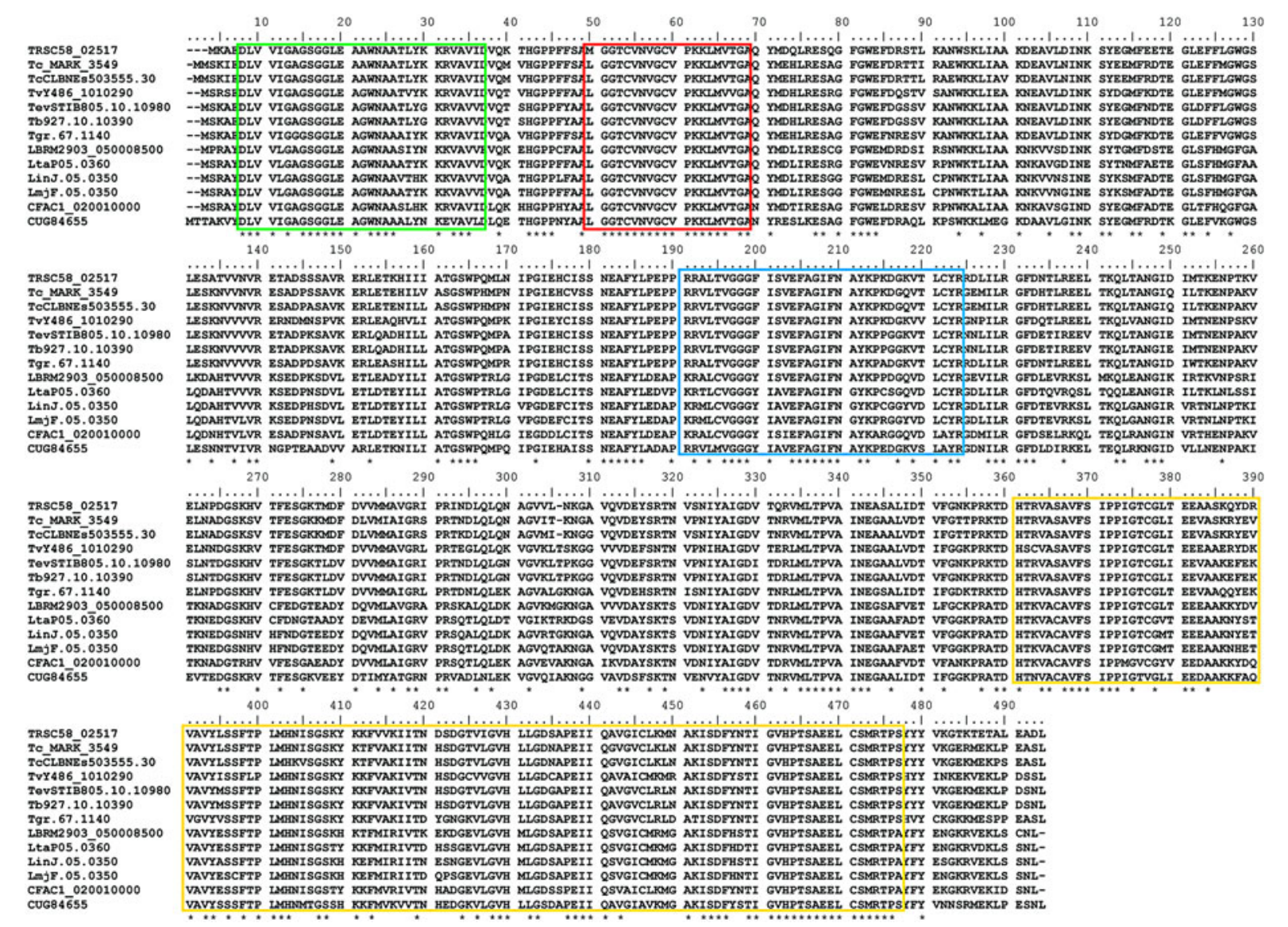

Fig. 1. Trypanosoma rangeli trypanothione reductase (TRed) has conserved catalytic domains. Alignment of the amino acid sequences of TRed from T. rangeli and other kinetoplastid species. Red rectangle- catalytic site; Green rectangleFAD binding domain; Blue rectangle- $\mathrm{NAD}(\mathrm{P})$ binding domains; Yellow rectangle- dimerization domain. Accession numbers for TRed from T. rangeli - TRSC58_02517; Trypanosoma cruzi marinkellei - Tc_MARK_3549; T. cruzi CLBrener - TcCLBNEs503555·30; Trypanosoma vivax- TvY486_1010290; Trypanosoma evansi-

TevSTIB805.10.10980; Trypanosoma brucei -Tb927.10.10390; Trypanosoma grayi - Tgr.67·1140; Leishmania braziliensis - LBRM2903_050008500; Leishmania tarentolae - LtaP05·0360; Leishmania infantum -LinJ.05·0350; Leishmania major LmjF.05·0350; Crithidia fasciculata - CFAC1_020010000; Bodo saltans - CUG84655.

epimastigotes and infective trypomastigotes. The results are shown in Fig. $3 \mathrm{C}$ and indicate a significant decrease in the mRNA levels of $\operatorname{Tr}$ TRed in trypomastigotes.

Having determined the basal TrTRed transcriptional and expression levels, we also evaluated whether $T r$ TRed expression by $T$. rangeli epimastigotes was influenced by $\mathrm{H}_{2} \mathrm{O}_{2}$-induced oxidative stress. The Western blotting shown in Fig. 4A indicates that there was no significant increase in $\operatorname{Tr}$ TRed expression up to $1 \mathrm{~h}$ after exposure to 67 $\mu \mathrm{M} \mathrm{H}_{2} \mathrm{O}_{2}$. This concentration of $\mathrm{H}_{2} \mathrm{O}_{2}$ was based on the $\mathrm{IC}_{50}$ determined in previous studies (Stoco et al. 2014; Romero et al. 2014). For all times and conditions tested, no significant differences were observed in the densitometric analysis, which indicated that $\operatorname{Tr}$ TRed expression by parasites remained constant regardless of exposure to oxidative stress.

Modulation of enzyme expression was evaluated during oxidative stress induced by hydrogen peroxide in $T$. rangeli, also considering the endogenous production of $\mathrm{H}_{2} \mathrm{O}_{2}$ by the parasite. Using the
DCFH-DA probe, we observed that oxidative stress induced by concentrations of $\mathrm{H}_{2} \mathrm{O}_{2}$ up to $125 \mu \mathrm{M}$ did not induce changes in fluorescence emission among treated and non-treated parasites. However, at concentrations of $250 \mu \mathrm{M}$ and higher, an effective and significant effect of the stressor was observed for both $T$. rangeli and T. cruzi in comparison with non- $\mathrm{H}_{2} \mathrm{O}_{2}$-treated parasites (Fig. 4B).

The amount of NADPH produced by $T$. rangeli epimastigotes, as determined by the combined measurement of G6PDH and 6PGD activities, was $1 \cdot 1 \pm$ $0.05 \mathrm{~nm} \mathrm{~min}^{-1} 10^{7}$ cells $^{-1}$, whereas $T$. cruzi epimastigotes produced $2.13 \pm 0.09 \mathrm{~nm} \mathrm{NADPH}$ min $^{-1}$ $10^{7}$ cells $^{-1}$. This difference was significantly different $(P<0.05)$ and indicated that the pentose pathway is more effective in $T$. cruzi than in the other parasite. Based on this difference and considering the distinct virulence of these species to their mammalian hosts, we determined the amount of mitochondrial hydrogen peroxide released by these parasites. Using digitonin-permeabilized cells and succinate as a substrate for the mitochondrial 

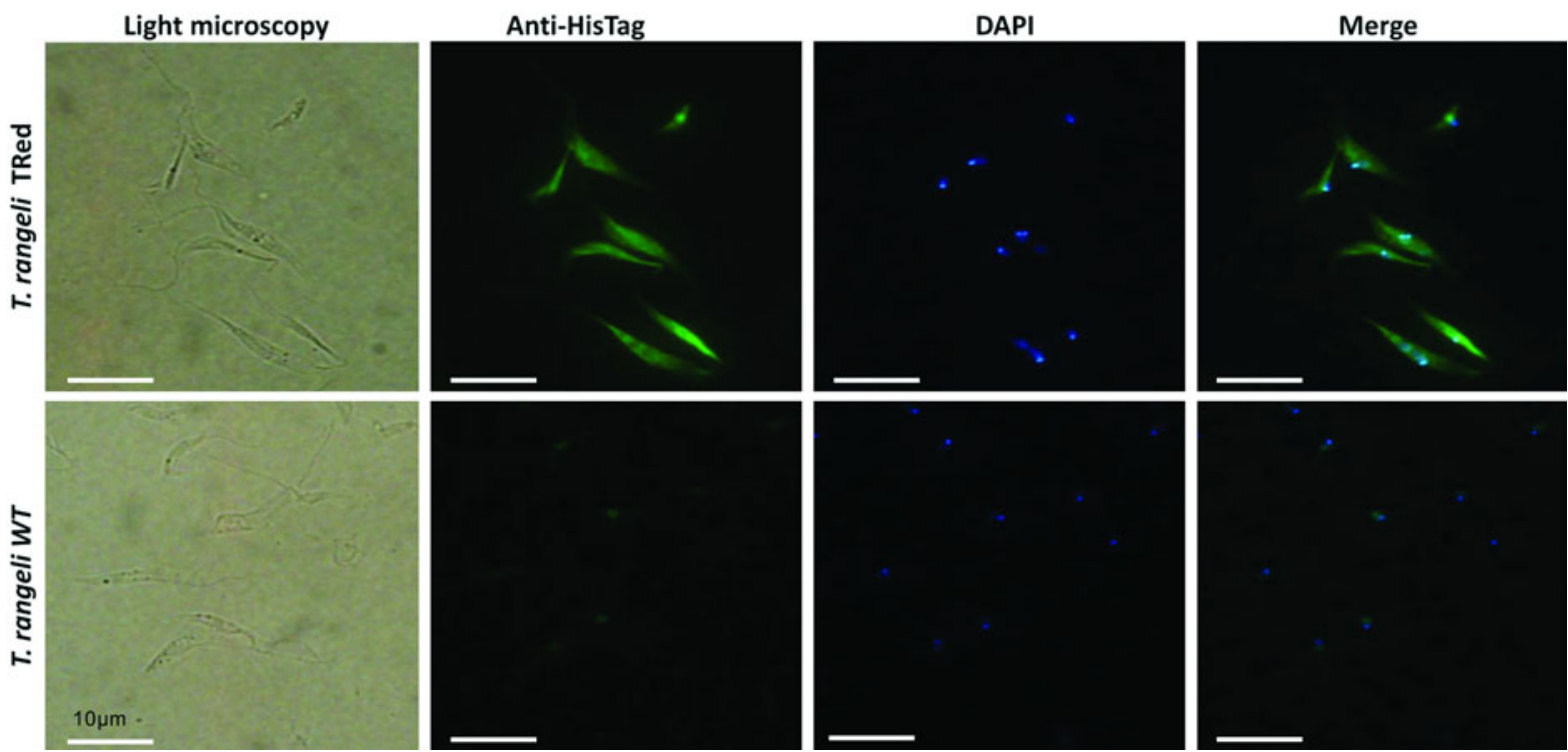

Fig. 2. Homologous trypanothione reductase overexpressed by Trypanosoma rangeli has a cytosolic localization.

Immunolocalization of the expression sites of $\mathrm{r} T r$ TRed in $T$. rangeli epimastigotes ( $T$. rangeli TRed) by IFA assays using anti-His6-tag antibody. T. rangeli wild type (WT) parasites were used as controls. (1) Light microscopy, (2) Detection of $\mathrm{r} T r$ TRed using anti-His6-tagged antibodies, (3) DAPI staining and (4) merged images. Bars indicate $10 \mu \mathrm{m}$.

A
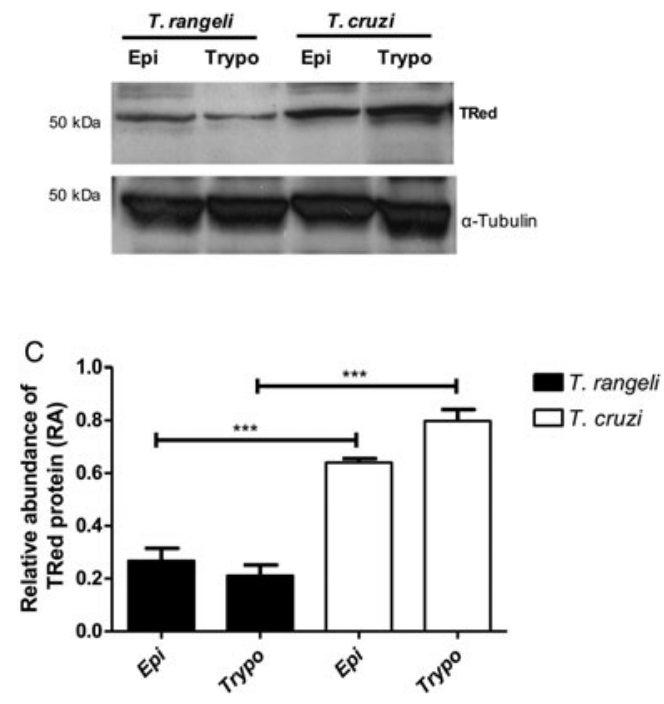
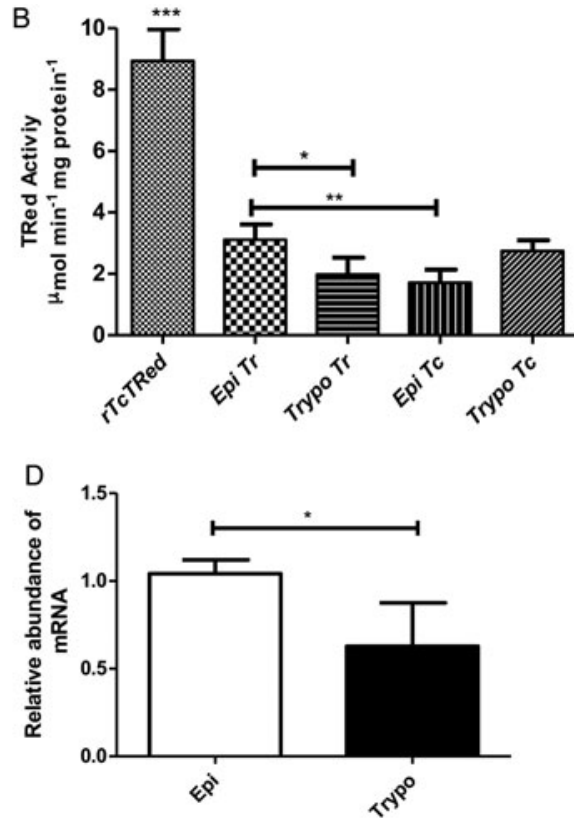

Fig. 3. TRed expression and activity are mainly observed in Trypanosoma rangeli epimastigotes. (A) Western blot analysis of TRed expression in soluble T. rangeli and T. cruzi protein extracts obtained from epimastigote (Epi) and trypomastigote (Trypo) forms and comparative densitometric analysis of the blotting results using ImageJ software. Significant differences were determined by one-way ANOVA followed by the Bonferroni test (*** $P<0 \cdot 001)$. Detection of $\alpha$-tubulin served as a loading control and for normalization of the densitometry analysis. (B) Enzymatic activity of TRed in soluble protein extracts of $T$. rangeli and T. cruzi epimastigotes and trypomastigotes. The recombinant T. cruzi TRed (rTc TRed) was used as a positive control, and the results represent the mean \pm s.D.M. (standard deviation of the mean) from 3 independent experiments performed in triplicate. Significant differences were assessed by one-way ANOVA followed by the Bonferroni test (*P<0.05, ** $P<0 \cdot 01$, *** $P<0 \cdot 001$ ). (C) Detection of $T r$ TRed mRNA levels in $T$. rangeli epimastigotes and trypomastigotes by qPCR using GAPDH and RNA60S for normalization. Data represent the mean \pm S.D.M. from two independent experiments conducted with technical quadruplicates. Significant differences were assessed by Student's $t$-test $(* P<0 \cdot 05)$. 
A

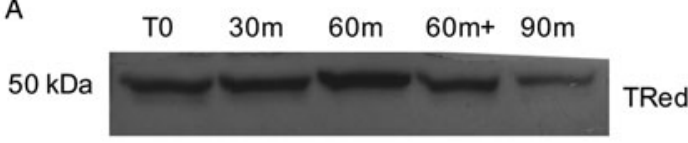

$50 \mathrm{kDa}$

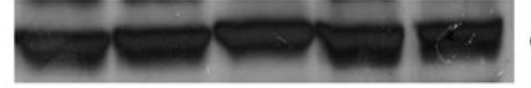

a-Tubulina

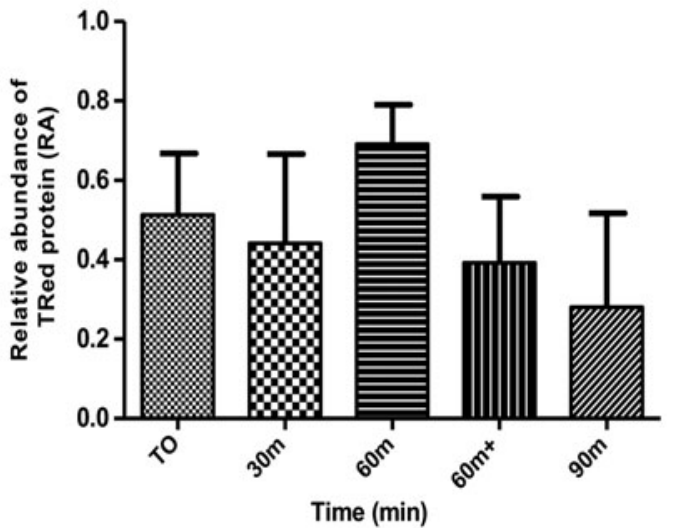

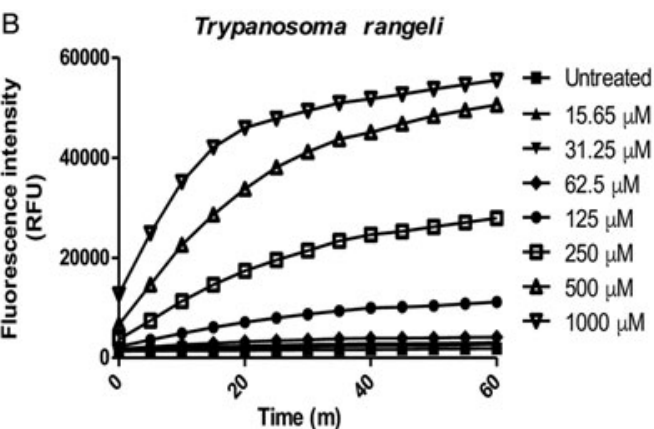

Trypanosoma cruzi

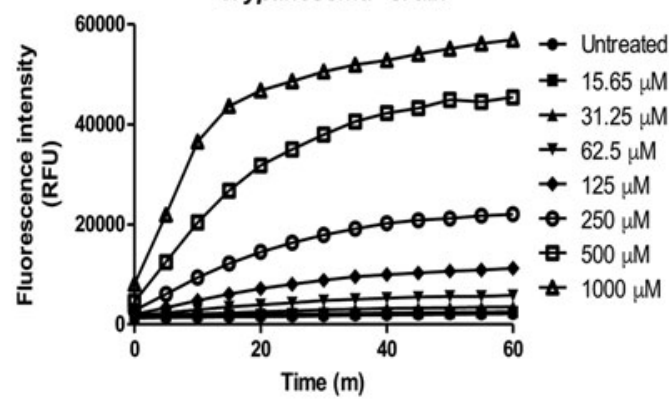

Fig. 4. Trypanosoma rangeli and Trypanosoma cruzi epimastigotes exhibit similar responses to in vitro oxidative stress induced by $\mathrm{H}_{2} \mathrm{O}_{2}$. (A) Western blot analysis of $T r$ TRed expression in soluble protein extracts obtained at different time points from $T$. rangeli epimastigotes under oxidative stress induced by $67 \mu \mathrm{M} \mathrm{H}_{2} \mathrm{O}_{2}$. Comparative densitometric analysis of the blotting results using Image J software. Data represent the mean \pm s.D.M. from three independent experiments.

Significant differences were assessed by one-way ANOVA followed by the Bonferroni post-hoc test (*P<0.05). Detection of $\alpha$-tubulin served as loading control and for normalization in the densitometry analysis. (B) Detection of fluorescence emitted by the DCFH-DA probe in parasites exposed to increasing concentrations of hydrogen peroxide. The results are expressed as the mean \pm s.D.M. from two independent experiments performed using technical quadruplicates. Significant differences were detected by one-way ANOVA following by the Bonferroni post-hoc test $(* * * P<0 \cdot 001)$.
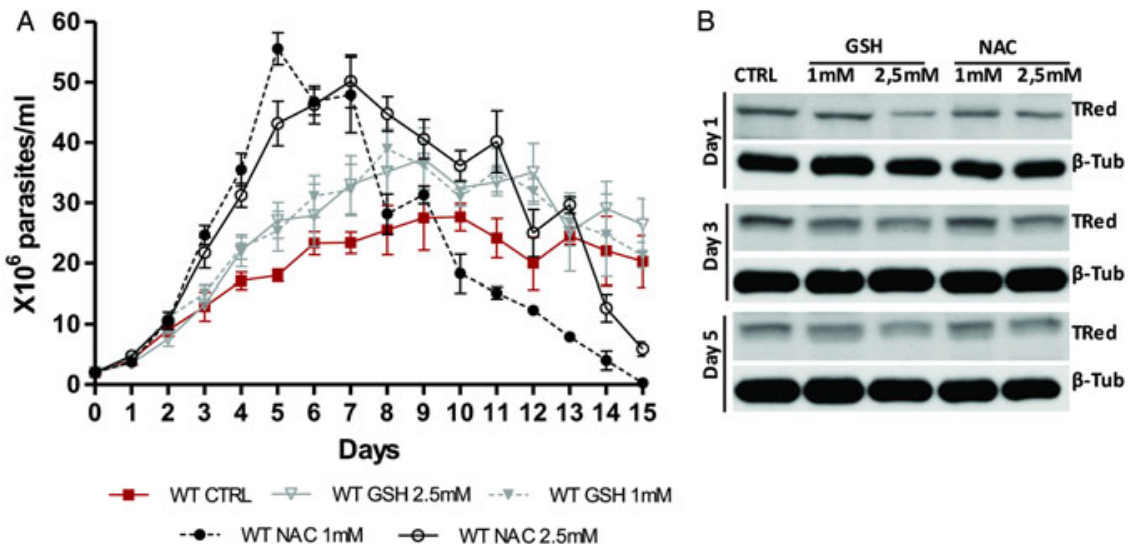

Fig. 5. N-acetylcysteine treatment improves the growth of Trypanosoma rangeli epimastigotes. (A) Comparative in vitro growth curve of $T$. rangeli submitted to treatments with GSH and NAC at 1 and $2.5 \mathrm{mM}$. The results are expressed as the mean \pm s.D.M. of triplicates. Significant differences were detected using two-way ANOVA followed by the Bonferroni posthoc test. (B) Representative Western blot analysis of $T r$ TRed expression in soluble protein extracts from $T$. rangeli with different treatments at days 1, 3 and 5 revealed by anti- $T c$ Red antibody. Detection of $\alpha$-tubulin served as a loading control and for normalization in the densitometry analysis.

respiratory chain, we were able to determine that $T$. rangeli epimastigotes released $14 \cdot 2 \pm 1 \cdot 6 \mathrm{pM}$ of $\mathrm{H}_{2} \mathrm{O}_{2}$ min $^{-1} 10^{7}$ cells $^{-1}$ (data not shown), which is higher than the levels observed for T. cruzi under the same experimental conditions (Silva et al. 2011).
The presence of antioxidants improved the in vitro growth of $T$. rangeli epimastigotes (Fig. 5A). Both treatments with NAC (1 and $2.5 \mathrm{~mm})$ induced dramatic growth of the parasites from day 3-7 $(P<$ $0 \cdot 001)$. Parasites grown in the presence of $1 \mathrm{~mm}$ 

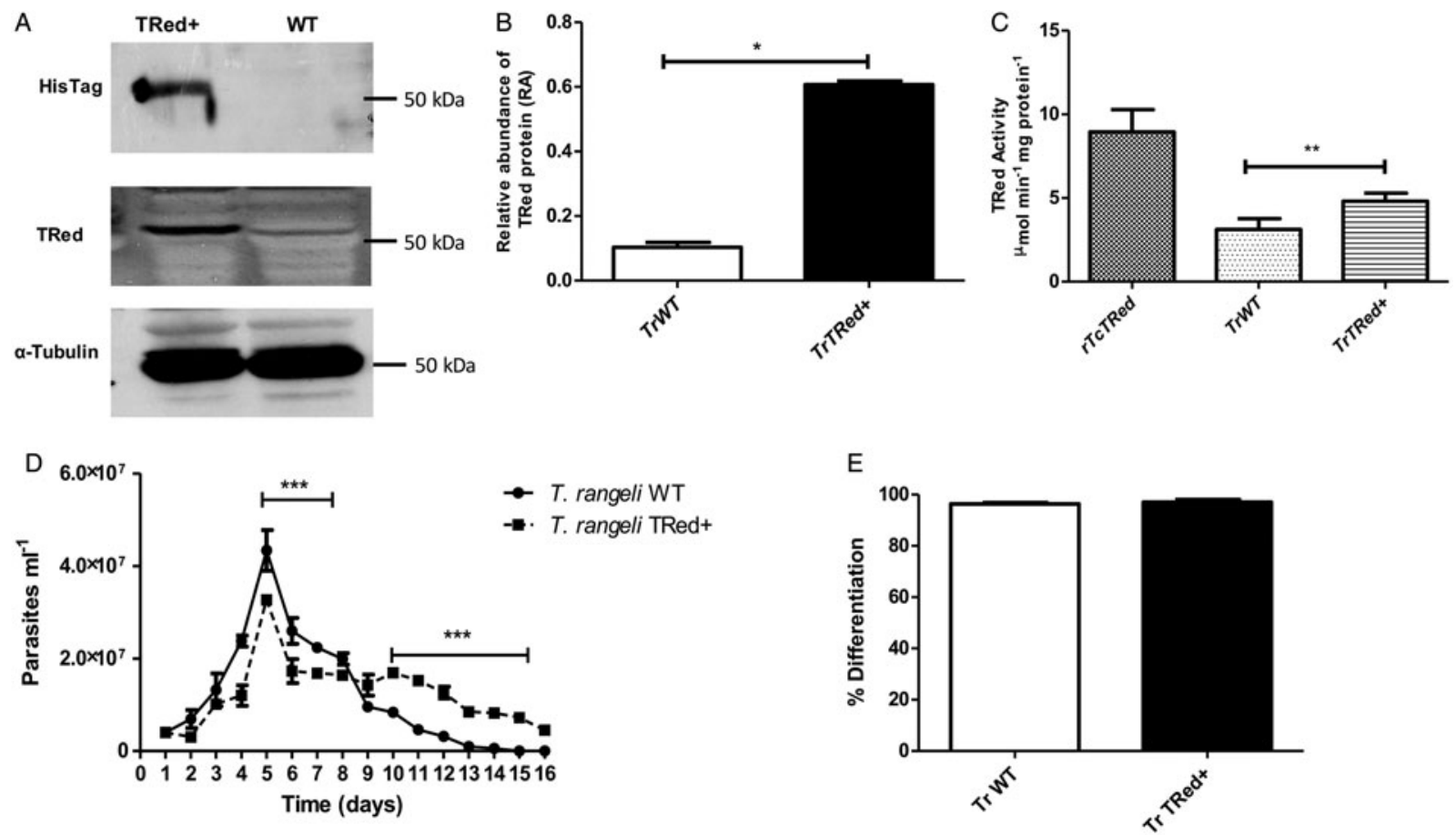

Fig. 6. Overexpression of TRed by Trypanosoma rangeli epimastigotes does not affect parasite biology in vitro. (A) Western blot analysis of $\operatorname{Tr}$ TRed expression in soluble protein extracts from $T$. rangeli overexpressing $\operatorname{Tr}$ TRed + and WT revealed by anti-His6-tag and anti- $T c$ Red antibodies. Detection of $\alpha$-tubulin served as a loading control and for normalization in the densitometry analysis. (B) Comparative densitometric analysis of the blotting results using ImageJ software. (C) TRed enzymatic activity in protein extracts from $T$. rangeli $\mathrm{W} T$ and $T r$ TRed+-overexpressing epimastigotes. $\mathrm{r} T c$ TRed was used as a control. (D) Comparative in vitro growth curve of $\operatorname{Tr}$ TRed + and WT T. rangeli strains starting from $4 \times 10^{6}$ parasites $\mathrm{mL}^{-1}$. (E) Comparative percentages of the in vitro differentiation of $T$. rangeli $\mathrm{WT}$ and TRed + mutants. The results shown in panels $\mathrm{B}$ and $\mathrm{C}$ represent the mean \pm S.D.M. obtained from three independent experiments using biological triplicates. For panels B and C, significant differences were assessed using Student's $t$-test $(* P<0 \cdot 05, * * P<0 \cdot 01)$. The results in panel $\mathrm{D}$ represent the mean \pm s.D.M. obtained from three independent experiments performed in duplicate.

Significant differences were assessed by two-way ANOVA (*** $P<0 \cdot 001)$.

NAC reached the largest number of parasites $(5 \cdot 8 \times$ $10^{7}$ parasites $\mathrm{mL}^{-1}$ ) on the 5 th day of culture. Treatments with GSH (1 and $2.5 \mathrm{~mm}$ ) also improved parasite growth from day 5-12 $(P<$ $0 \cdot 01)$. Although important differences in parasite growth were observed in the presence of antioxidants, the reducing environment did not affect the expression of TRed (Fig. 5B). The protein levels remained constant in parasites grown under different conditions on the days evaluated.

Overexpression of homologous $\operatorname{Tr}$ TRed by $T$. rangeli epimastigotes revealed a 5 -fold increase in the protein expression level compared with wild type parasites (Fig. 6A and B). As expected, the specific TRed activity in parasites overexpressing this gene was $1 \cdot 3$-fold higher than the TRed activity in control W'T parasites (Fig. 6C). Overexpression of $T r$ TRed by $T$. rangeli revealed no major differences in in vitro growth when compared with WT parasites (Fig. 6D). The maximum number of parasites for both WT $\left(4 \cdot 3 \times 10^{7}\right.$ parasites $\left.\mathrm{mL}^{-1}\right)$ and overexpressing parasites $\left(3.3 \times 10^{7}\right.$ parasites $\left.\mathrm{mL}^{-1}\right)$ was observed on day 5 of culture. While the growth curve of the wild type strain exhibited a typical decrease in the number of live parasites from day 6 forward, overexpressing parasites appeared to be sustained in culture up to day 14 and then started to decrease. Significant differences were observed in comparisons of the number of parasites between days 4-7 and 10-15. We may conclude that TrTRed-overexpressing parasites have slightly higher growth and survival rates in vitro compared with W'T parasites. It is noteworthy that overexpression of $T r$ TRed had no effect on the ability of parasites to undergo in vitro differentiation into infective trypomastigotes compared with the parental WT strain (Fig. 6E).

Parasites overexpressing $T r$ TRed protein were also more resistant $(2 \cdot 3$ times $)$ to $\mathrm{H}_{2} \mathrm{O}_{2}$ than wildtype parasites. The dose-response analysis revealed a marked difference in resistance to $\mathrm{H}_{2} \mathrm{O}_{2}$ between $T$. rangeli WT and mutant strains at the $125 \mu \mathrm{M}$ $\mathrm{H}_{2} \mathrm{O}_{2}$ concentration, in which the viability of the mutant parasites was 13.4-fold higher compared with the WT parasites (Fig. 7A).

Due to this increased resistance to $\mathrm{H}_{2} \mathrm{O}_{2}$ stress, we also assessed whether the increased expression of $\operatorname{Tr}$ TRed by $T$. rangeli would modulate its ability to infect and survive within a phagocytic cell. Although $\operatorname{Tr}$ TRed-overexpressing parasites seemed 
A
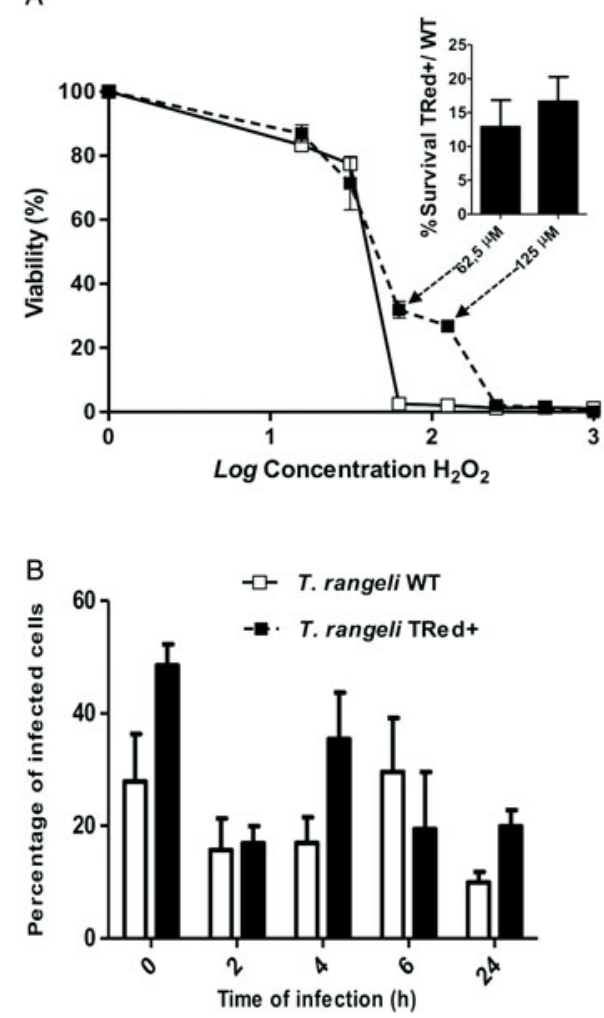

C

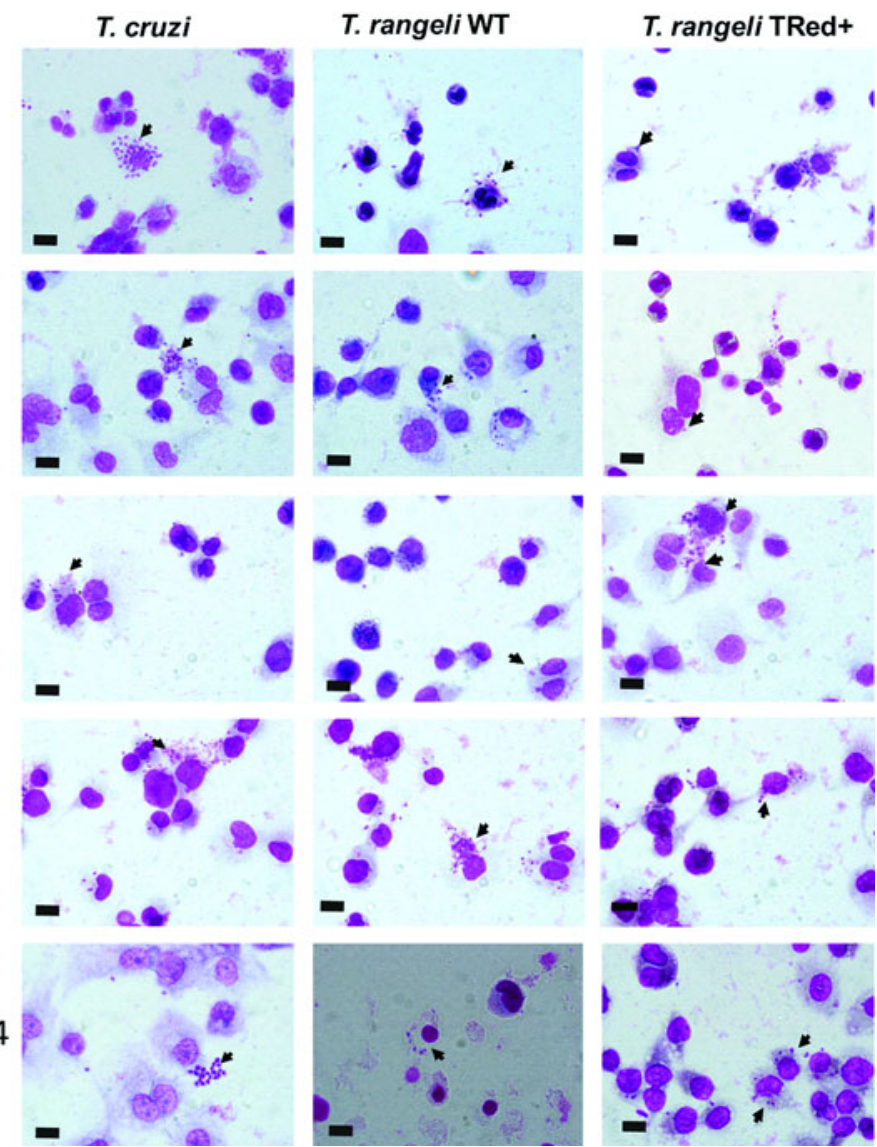

Fig. 7. Overexpression of homologous $T r$ TRed by Trypanosoma rangeli epimastigotes increases parasite survival under oxidative stress in vitro. (A) Viability of $T$. rangeli $\mathrm{WT}$ and $T r \mathrm{TRed}+$ epimastigotes in response to increasing concentrations of $\mathrm{H}_{2} \mathrm{O}_{2}$ assessed by Alamar Blue staining. The bars represent the survival ratio between $\operatorname{Tr} \mathrm{TRed}+$ and WT at 62,5 and $125 \mu \mathrm{M}$. (B) The percentages of THP-1 cells infected by T. rangeli WT or TrTRed+ mutants during the time course of the in vitro cell-parasite interaction. (C) Light micrographs of distinct time points (T0-T24 hours) of THP1-derived human macrophages infected by $T$. rangel $i$ WT or $T r$ Tred + mutants. Trypanosoma cruzi-infected THP- 1 cells were used as a control. Cells were stained with Giemsa, black arrows indicate parasites and bars represent $10 \mu \mathrm{M}$. The results shown in panels $\mathrm{A}$ and $\mathrm{B}$ represent the mean \pm s.D.M. from three independent experiments performed in triplicate.

to be more infective on $\mathrm{T} 0, \mathrm{~T} 4$ and $\mathrm{T} 24$, the kinetic study of the interaction of WT and mutant parasites with THP1-derived macrophages in vitro revealed no significant differences between the parasite strains $(P$ $<0.05)$ in terms of the number of infected cells (Fig. 7B and C). No signs of $T$. rangeli multiplication were observed for WT or mutant parasites. In conclusion, increased expression of homologous TRed by $T$. rangeli enhanced its resistance to oxidative stress but did not induce detectable phenotypic changes in the in vitro parasite-THP-1 cell interactions.

\section{DISCUSSION}

Members of the Trypanosomatidae family are digenetic parasites with a life cycle that presents multiple differentiation forms alternating between invertebrate and vertebrate hosts (Teixeira and DaRocha, 2003). During each stage of differentiation, a stagespecific protein expression pattern participates in the invasion and survival processes of the parasite (Macleod et al. 2007; Díaz et al. 2011).
Redox homoeostasis appears to be efficiently regulated in kinetoplastids because the parasites can successfully survive the oxidative burst generated at the onset of infection and adapt to the different metabolic and environmental conditions (Peloso et al. 2012). At present, antioxidant defence is directly related to the success of the infection process because the proteins making up this system are among those that are most expressed during differentiation from replicative epimastigotes to infective trypomastigotes (Atwood et al. 2005; Piñeyro et al. 2008; Piacenza et al. 2009a, b; Gretes et al. 2012). In T. cruzi, increased expression of antioxidant defence-related proteins enables the parasite to survive in the complex and highly oxidative environment within macrophages (Atwood et al. 2005; Araujo and Teixeira, 2011). According to Irigóin et al. (2008), this increase is a preadaptation of the parasite prior to invasion of the vertebrate host in preparation for environments in which it may be exposed to ROS and RNS (reactive nitrogen species) such as those generated by immune cells. However, an evaluation 
of antioxidant enzymes in $T$. cruzi virulent strains compared with attenuated ones revealed that the protein contents observed in Tc'TRed remained constant across the different parasites stages (Piacenza et al. 2009a, b).

The susceptibility of $T$. rangeli to oxidative stress was evaluated by subjecting epimastigotes to $\mathrm{H}_{2} \mathrm{O}_{2}$ induced stress conditions in vitro according to Stoco et al. (2014) and Romero et al. (2014). These authors demonstrated that $T$. rangel $i$ was more sensitive than T. cruzi to oxidative stress, showing an $\mathrm{IC}_{50}$ of 53 $\mu \mathrm{M}$, which is significantly less than the $\mathrm{IC}_{50}$ obtained for $T$. cruzi epimastigotes $(188 \cdot 3 \mu \mathrm{M})$. Previous studies using distinct $T$. cruzi strains have shown a wide range of $\mathrm{IC}_{50}$ for the $\mathrm{H}_{2} \mathrm{O}_{2}$ stress, varying from 98 to $190 \mu \mathrm{M}$ (Finzi et al. 2004; MielniczkiPereira et al. 2007).

Taylor et al. (1994) described an absence of Leishmania donovani TRed expression modulation during the induction of oxidative stress by $\mathrm{H}_{2} \mathrm{O}_{2}$. These authors state that in contrast to peroxidases, which are upregulated due to direct involvement in the detoxification of $\mathrm{H}_{2} \mathrm{O}_{2}$-induced stress, TRed is not directly involved in such detoxification. For $T$. rangeli, TRed appears to be constitutively expressed during the parasite life cycle, as described in this study and in accordance with Taylor et al. (1994). It also appears to participate in the mechanisms that protect the parasite from ROS. Although the results obtained herein were obtained from only one strain of each species ( $T$. rangeli Choachí and $T$. cruzi $\mathrm{Y}$ ), they yielded some interesting insights regarding comparisons of the antioxidant defence of these parasites.

Although expressed during the entire life cycle of $T$. rangeli, elevated activity of $T r$ TRed was observed during the replicative epimastigote stage. Unlike $T$. $c r u z i$, which faces oxidative stresses in the mammalian host and within the digestive tract of the triatomine vector, $T$. rangeli epimastigotes are found within the intestinal tract and haemolymph of triatomines, where the parasite is exposed to successive and distinct oxidative and/or nitrosative stresses. In this study, reduced $T r$ TRed expression was observed for the in vitro-derived trypomastigote forms. Because these parasites are biochemically distinct from the $T$. rangeli metacyclics observed within the triatomine salivary glands and bloodstream trypomastigotes found in infected mammals, the reduced $\operatorname{Tr}$ TRed expression observed in vitroderived trypomastigotes remains to be examined in in vivo parasites.

The present observations can be related to a reduction in NADPH production in $T$. rangeli compared with T. cruzi epimastigotes. Unlike T. cruzi, $T$. rangeli is able to evade the intestinal tract of the triatomine by penetrating through the gut epithelium towards the haemocoel, where the parasites undergo successive division cycles prior to invading the salivary glands (Stoco et al. 2014). These highly oxidative environments (Garcia et al. 2009) demand increased synthesis of NADPH by the parasite as a primary source of reducing equivalents for biosynthetic reactions and the oxidation-reduction involved in protecting against the toxicity of ROS (Igoillo-Esteve et al. 2007; Leroux et al. 2010). In this sense, several enzymes are also co-responsible for the maintenance of this reducing environment, such as the NADP-linked glutamate dehydrogenase (Barderi et al. 1998), the NADP-linked malic enzyme (Cannata et al. 1979) and the two dehydrogenases in the pentose phosphate pathway (PPP) (Leroux et al. 2010), which is the major source of reduced TRed (Krauth-Siegel and Comini, 2008; Leroux et al. 2010; Peloso et al. 2011).

By analysing the PPP-related enzymes in different T. cruzi life stages, Maugeri and Cazzulo (2004) demonstrated increased expression in trypomastigotes that probably resulted from the need to respond to the oxidative stress created by the mammalian host.

Trypanosoma cruzi and T. brucei depend on their NADP-linked dehydrogenases, such as malic enzymes, for NADPH production in low or no glucose environments, in the gut of their insect vectors or within cells, because under such conditions, the PPP cannot act as a source of essential redox mechanisms (Hellemond et al. 2005; Leroux et al. 2010; Allman et al. 2013). The relative roles of the PPP and alternative reactions to provide NADPH have not yet been investigated in $T$. rangeli.

The major and continuous source of cellular ROS, including $\mathrm{H}_{2} \mathrm{O}_{2}$, is the mitochondrial electron transport chain. $\mathrm{H}_{2} \mathrm{O}_{2}$ can easily diffuse through the plasma membrane and interact with membranebound components (Cosentino-Gomes et al. 2009). As determined in this study, endogenous production of $\mathrm{H}_{2} \mathrm{O}_{2}$ was higher in $T$. rangeli than in $T$. cruzi (Peloso et al. 2011). This distinct behaviour could be due to differences in the mitochondrial antioxidant defences of the two species. In addition to the reduced TRed expression compared with T. cruzi, the reduced NAPDH production and higher susceptibility to $\mathrm{H}_{2} \mathrm{O}_{2}$-induced stress by $T$. rangeli allowed us to hypothesize that these two species have distinct superoxide dismutase expression profiles. Thus, it is noteworthy that overexpression of superoxide dismutase by $T$. cruzi induces a reduced sensitivity to trypanocidal agents (Temperton et al. 1998).

$\mathrm{N}$-acetylcysteine (NAC) has been widely used as an antioxidant in vivo and in vitro. It is a powerful scavenger of hypochlorous acid (H--OCl) and reacts with hydroxyl radical and $\mathrm{H}_{2} \mathrm{O}_{2}$ (Aruoma et al. 1989; Rossato et al. 2014). GSH is the major intracellular antioxidant thiol that protects mammalian cells against oxidative stress induced by oxygenand nitrogen-derived reactive species (Romão et al. 
1999). Our results demonstrated that the presence of these antioxidants (NAC and GSH) promoted improved growth of epimastigotes cultivated in LIT medium. Conversely, the presence of the same antioxidants dramatically impaired T. cruzi epimastigote proliferation (Nogueira et al. 2015), and the presence of the pro-antioxidant heme induced epimastigote proliferation. Thus, $T$. rangeli appeared to require a reduced environment for epimastigote proliferation, whereas T. cruzi required an oxidative environment. Both parasites develop inside triatomines; however, differences related to the biological cycle of these parasites in this host could explain the differences in proliferation. Epimastigotes from T. cruzi multiply and colonize the entire gut (oxidative environment), whereas $T$. rangeli epimastigotes rapidly cross the gut epithelium and invade the haemolymph. The haemolymph of Rhodnius prolixus has been described to have ten times more urate than human plasma (Souza et al. 1997; Graça-Souza et al. 2006). Urate is considered as one of the most important antioxidants in human plasma. Thus, the effect of the antioxidants NAC and GSH in T. rangeli cultures would improve their ability to grow by simulating the role of urate in the haemolymph. Despite the improved growth and reducing environment, we did not observe any modifications in the expression levels of $\operatorname{Tr}$ TRed.

The role of TRed in T. rangeli, like in T.cruzi and L. donovani (Kelly et al. 1993; Tovar et al. 1998), has been investigated by overexpressing the homologous enzyme. Kelly et al. (1993) transfected L. donovani and $T$. cruzi with an expression vector containing the $L d$ TRed gene and achieved 10-14-fold enzyme activity in transformed cells. Trypanosoma cruzi cells overexpressing the sense construct displayed a 4-fold increase in TRed protein levels and enzyme activity (Tovar and Fairlamb, 1996). The difference between the species is probably due to the distinct basal expression levels of TRed.

In addition to numerous tools used to unravel the mechanisms of T. cruzi infection, such as cellular tropism, infectivity and intracellular replication, in vitro infection of cell cultures has been utilized (Duran-Rehbein et al. 2014). Non-epithelial cells such as monocytes/macrophages are highly parasitized after very short incubation times, providing insight into the initial stages of T. cruzi infection and the subsequent immune response. Furthermore, survival within active macrophages seems to be highly dependent on the efficiency of ROS reduction (Leirião et al. 2004; Piacenza et al. 2008, 2013).

By overexpressing the homologous $\operatorname{Tr}$ TRed, we have demonstrated an apparent increase in the ability of $T$. rangeli to address the intracellular reducing environment within human macrophages, where there is a high demand for trypanothione
(Dumas et al. 1997). This study also indicates that TRed does not appear to be a pivotal molecule involved in the response of $T$. rangeli to antioxidant environments in vertebrate host cells; however, it plays a role in other parts of the parasite life cycle, such as in the insect gut or haemocytes where ROS production limits the infection and colonization of $R$. prolixus by $T$. rangeli (Cosentino-Gomes et al. 2014).

ROS have been traditionally viewed as a 'necessary evil' in the battle against pathogens, and their production is coupled to antioxidant responses that are important for mitigating oxidative damage in cells and tissues (Andrews, 2012). However, Paiva et al. (2012) and Goes et al. (2016) have demonstrated that oxidative stress actually enhances infection by the protozoan $T$. cruzi. In others words, T. cruzi seems to thrive in an oxidative environment, and antioxidant responses suppress infections by this protozoan parasite. Likewise, Leishmania donovani promastigotes treated with sub-lethal doses of $\mathrm{H}_{2} \mathrm{O}_{2}$ have been found to be more virulent and more potent for infecting macrophages ex vivo via a metabolic reconfiguration designed to replenish the NADPH pool for protection against oxidative challenges.

Therefore, future investigations will be designed to elucidate the role of ROS during $T$. rangeli infection. In this work, the role of $\mathrm{H}_{2} \mathrm{O}_{2}$ appeared to be a determinant in the host protection against parasite infection, and the inability of the parasite to respond to oxidative stress is directly related to its virulence.

\section{ACKNOWLEDGEMENTS}

To Dr. Silvane Murta (CPqRR/Fiocruz) for the antiTc TRed antibody. To Dr. Ibeth Romero, Dr. Milene Höehr de Moraes, Ana Paula Nascimento, MSc., Carime Lessa Mansur Pontes, MSc and Carine Lais Moreira for technical assistance and discussions.

\section{FINANCIAL SUPPORT}

To Conselho Nacional de Desenvolvimento Científico e Tecnológico - CNPq (E.C.G.), Coordenação de Aperfeiçoamento de Pessoal de Nível Superior - CAPES (E.C.G.) and Fundação de Amparo à Pesquisa do Estado de São Paulo - FAPESP (F.R.G.) - Brazilian Government Agencies. To the STINT (Sweden)/ CAPES (Brazil) joint program (B.A./E.C.G.).

\section{CONFLICT OF INTEREST}

The authors declare no conflicts of interest.

\section{ETHICAL STANDARDS}

All procedures involving animals were previously approved by the Ethical Committee on Animal Use of Federal University of Santa Catarina (Reference number 23080·025618/2009-81). 


\section{REFERENCES}

Allman, S., Morand, P., Ebikeme, C., Gales, L., Biran, M., Hubert, J., Brennand, A., Mazet, M., Franconi, J. M., Michels, P. A. M., Portais, J. C., Boshart, M. and Bringaud, F. (2013). Cytosolic NADPH homeostasis in glucose-starved procyclic Trypanosoma brucei relies on malic enzyme and the pentose phosphate pathway fed by gluconeogenic flux. Fournal of Biological Chemistry 288, 18494-18505

Andrews, N. W. (2012). Oxidative stress and intracellular infections: more iron to the fire. Fournal of Clinical Investigation 122, 2352-2354.

Araujo, P. R. and Teixeira, S. M. (2011). Regulatory elements involved in the post-transcriptional control of stage-specific gene expression in Trypanosoma cruzi: a review. Memórias do Instituto Oswaldo Cruz 106, 257-266

Aruoma, O. I., Halliwell, B., Hoey, B. M. and Butler, J. (1989). The antioxidant action of $\mathrm{N}$-acetylcysteine: its reaction with hydrogen peroxide, hydroxyl radical, superoxide, and hypochlorous acid. Free Radical Biology \& Medicine 6, 593-597.

Aslett, M., Aurrecoechea, C., Berriman, M., Brestelli, J., Brunk, B. P., Carrington, M. and Wang, H. (2010). TriTrypDB: a functional genomic resource for the Trypanosomatidae. Nucleic Acids Research 38, D457-D462.

Altschul, S. F., Gish, W., Miller, W., Myers, E. W. and Lipman, D. J. (1990). Basic local alignment search tool. Fournal of Molecular Biology 215, 403-410.

Atwood, J. A., Weatherly, D. B., Minning, T. A., Bundy, B., Cavola, C., Opperdoes, F. R., Orlando, R. and Tarleton, R. L. (2005). The Trypanosoma cruzi proteome. Science 309, 473-476.

Azambuja, P., Ratcliffe, N. A. and Garcia, E. S. (2005). Towards an understanding of the interactions of Trypanosoma cruzi and Trypanosoma rangeli within the reduviide insect host Rhodnius prolixus. Anais da Academia Brasileira de Ciências 77, 397-404.

Barderi, P., Campetella, O., Frasch, A. C. C., Santomé, J. A., Hellman, U., Pettersson, U. and Cazzulo, J. J. (1998). The NADPlinked glutamate dehydrogenase from Trypanosoma cruzi: sequence, genomic organization and expression. Biochemical fournal 330, 951-958.

Barros, M. H., Bandy, B., Tahara, E. B. and Kowaltowski, A. J. (2004). Higher respiratory activity decreases mitochondrial reactive oxygen release and increases life span in Saccharomyces cerevisiae. Fournal of Biological Chemistry 279, 49883-49888.

Bradford, M. M. (1976). A rapid and sensitive method for the quantitation of microgram quantities of protein utilizing the principle of protein-dye binding. Analytical Biochemistry 72, 248-254.

Cannata, J. J. B., Frasch, A. C. C., Cataldi De Flombaum, M. A., Segura, E. L. and Cazzulo, J. J. (1979). Two forms of malic enzyme with different regulatory properties in Trypanosoma cruzi. Biochemical Fournal 184, 409-419.

Coura, J. R., Fernandes, O., Arboleda, M., Barrett, T. V., Carrara, N., Degrave, W. and Campbell, D. A. (1996). Human infection by Trypanosoma rangeli in the Brazilian Amazon. Transactions of the Royal Society of Tropical Medicine and Hygiene 90, 278-279.

Cosentino-Gomes, D., Russo-Abrahão, T., Fonseca-de-Souza, A. L., Ferreira, C. R., Galina, A. and Meyer-Fernandes, J. R. (2009). Modulation of Trypanosoma rangeli ecto-phosphatase activity by hydrogen peroxide. Free Radical Biology and Medicine 47, 152-158.

Cosentino-Gomes, D., Rocco-Machado, N. and MeyerFernandes, J. R. (2014). Rhodnius prolixus: modulation of antioxidant defenses by Trypanosoma rangeli. Experimental Parasitology 145, 118-124. Decuypere, S., Vanaerschot, M., Brunker, K., Imamura, H., Müller, S., Khanal, B., Rijal, S., Dujardin, J. C. and Coombs, G. H. (2012). Molecular mechanisms of drug resistance in natural Leishmania populations vary with genetic background. PLOS Neglected Tropical Diseases 6, e1514

Díaz, M. L., Solari, A. and González, C. I. (2011). Differential expression of Trypanosoma cruzi I associated with clinical forms of Chagas disease: overexpression of oxidative stress proteins in acute patient isolate. Fournal of Proteomics 74, 1673-1682.

Dumas, C., Ouellette, M., Tovar, J., Cunningham, M. L., Fairlamb, A. H., Tamar, S., Olivier, M. and Papadopoulou, B. (1997). Disruption of the trypanothione reductase gene of Leishmania decreases its ability to survive oxidative stress in macrophages. EMBO fournal 16, 2590-2598.

Duran-Rehbein, G. A., Vargas-Zambrano, J. C., Cue'llar, A., Puerta, C. J. and Gonzalez, J. M. (2014). Mammalian cellular culture models of Trypanosoma cruzi infection: a review of the published literature. Parasite 21, 1-9.
Eger-Mangrich, I., De Oliveira, M. A., Grisard, E. C., De Souza, W. and Steindel, M. (2001). Interaction of Trypanosoma rangeli Tejera, 1920 with different cell lines in vitro. Parasitology Research 87, 505-509.

Ewing, B., Hillier, L., Wend1, M. C. and Green, P. (1998). Base-calling of automated sequencer traces using phred. I. Accuracy assessment. Genome Research 8, 175-185.

Fairlamb, A. H., Blackburn, P., Ulrich, P., Chait, B. T. and Cerami, A. (1985). Trypanothione: a novel bis (glutathionyl) spermidine cofactor for glutathione reductase in trypanosomatids. Science 227, 1485 1487.

Fairlamb, A. H. and Cerami, A. (1992). Metabolism and functions of trypanothione in the Kinetoplastida. Annual Review of Microbiology 46, 695-729.

Ferreira, L. L., Lorenzo, M. G., Elliot, S. L. and Guarneri, A. A (2010). A standardizable protocol for infection of Rhodnius prolixus with Trypanosoma rangeli, which mimics natural infections and reveals physiological effects of infection upon the insect. Fournal of Invertebrate Pathology 105, 91-97.

Finzi, J. K., Chiavegatto, C. W., Corat, K. F., Lopez, J. A., Cabrera, O. G., Mielniczki-Pereira, A. A., Colli, W., Alves, M. J. and Gadelha, F. R. (2004). Trypanosoma cruzi response to the oxidative stress generated by hydrogen peroxide. Molecular and Biochemical Parasitology 133, 37-43.

Flohé, L. (2012). The trypanothione system and its implications in the therapy of trypanosomatid diseases. International fournal of Medical Microbiology 302, 216-220.

Gallagher, S., Winston, S. E., Fuller, S. A. and Hurrell, J. G. (2008). Immunoblotting and immunodetection. Current Protocols in Molecular Biology 83, III:10·8: $10 \cdot 8 \cdot 1-10 \cdot 8 \cdot 28$

Garcia, E. S., Castro, D. P., Figueiredo, M. B., Genta, F. A. and Azambuja, P. (2009). Trypanosoma rangeli: a new perspective for studying the modulation of immune reactions of Rhodnius prolixus. Parasites $\xi^{\circ}$ Vectors 2, 1-10.

Goes, G. R., Rocha, P. S., Diniz, A. R. S., Aguiar, P. H. N., Machado, C. R. and Vieira, L. Q. (2016). Trypanosoma cruzi needs a signal provided by reactive oxygen species to infect macrophages. PLOS Neglected Tropical Diseases 10, e0004555.

Graça-Souza, A. V., Maya-Monteiro, C., Paiva-Silva, G. O. Braz, G. R. C., Paes, M. C., Sorgine, M. H., Oliveira, M. F. and Oliveira, P. L. (2006). Adaptations against heme toxicity in bloodfeeding arthropods. Insect Biochemistry and Molecular Biology 36, 322-335. Gretes, M., Poole, L. B. and Karplus, P. A. (2012). Peroxiredoxins in parasites. Antioxidants \& Redox Signaling 17, 608-633.

Grisard, E. C., Steindel, M., Guarneri, A. A., Eger-Mangrich, I., Campbell, D. A. and Romanha, A. J. (1999). Characterization of Trypanosoma rangeli strains isolated in Central and South America: an overview. Memórias do Instituto Oswaldo Cruz 94, 203-209.

Guhl, F. and Vallejo, G. A. (2003). Trypanosoma (Herpetosoma) rangeli Tejera, 1920: an updated review. Memórias do Instituto Oswaldo Cruz 98 $435-442$.

Hellemond, J. J. V., Opperdoes, F. R. and Tielens, A. G. M. (2005) The extraordinary mitochondrion and unusual citric acid cycle in Trypanosoma brucei. Biochemical Society Transactions 33, 967-971.

Igoillo-Esteve, M., Maugeri, D., Stern, A. L., Beluardi, P. and Cazzulo, J. J. (2007). The pentose phosphate pathway in Trypanosoma cruzi: a potential target for the chemotherapy of Chagas disease. Anais da Academia Brasileira de Ciências 79, 649-663.

Irigoín, F., Cibils, L., Comini, M. A., Wilkinson, S. R., Flohé, L. and Radi, R. (2008). Insights into the redox biology of Trypanosoma cruzi: Trypanothione metabolism and oxidant detoxification. Free Radical Biology \& Medicine 45, 733-742.

Jockers-Scherübl, M. C., Schirmer, R. H. and Krauth-Siegel, R. L. (1989). Trypanothione reductase from Trypanosoma cruzi. Catalytic properties of the enzyme and inhibition studies with trypanocidal compounds. European fournal of Biochemistry 180, 267-272.

Kelly, J. M., Taylor, M. C., Smith, K., Hunter, K. J. and Fairlamb, A. H. (1993). Phenotype of recombinant Leishmania donovani and Trypanosoma cruzi which over-express trypanothione reductase. Sensitivity towards agents that are thought to induce oxidative stress. European Fournal of Biochemistry 218, 29-37.

Koerich, L. B., Emmanuelle-Machado, P., Santos, K., Grisard, E. C. and Steindel, M. (2002). Differentiation of Trypanosoma rangeli: high production of infective trypomastigote forms in vitro. Parasitology Research 88, 21-25.

Krauth-Siegel, R. L. and Comini, M. A. (2008). Redox control in trypanosomatids, parasitic protozoa with trypanothione-based thiol metabolism. Biochimica et Biophysica Acta 1780, 1236-1248. 
Krieger, S., Schwarz, W., Ariyanayagam, M. R., Fairlamb, A. H., Krauth-Siegel, R. L. and Clayton, C. (2000). Trypanosomes lacking trypanothione reductase are avirulent and show increased sensitivity to oxidative stress. Molecular Microbiology 35, 542-552.

Leirião, P., Rodrigues, C. D., Albuquerque, S. S. and Mota, M. M. (2004). Survival of protozoan intracellular parasites in host cells. EMBO Reports 5, 1142-1147.

Leroux, A. E., Maugeri, D. A., Opperdoes, F. R., Cazzulo, J. J. and Nowicki, C. (2010). Comparative studies on the biochemical properties of the malic enzymes from Trypanosoma cruzi and Trypanosoma brucei FEMS Microbiology Letters 314, 25-33.

Livak, K. J. and Schmittgen, T. D. (2001). Analysis of relative gene expression data using real-time quantitative PCR and the 2(-Delta Delta C (T)) Method. Methods 25, 402-408.

Macleod, E. T., Maudlin, I., Darby, A. C. and Welburn, S. C. (2007) Antioxidants promote establishment of trypanosome infections in tsetse. Parasitology 134, 827-831

Maugeri, D. and Cazzulo, J. J. (2004). The pentose phosphate pathway in Trypanosoma cruzi. FEMS Microbiology Letters 234, 117-123.

Mielniczki-Pereira, A. A., Chiavegatto, C. M., López, J. A., Colli, W., Alves, M. J. and Gadelha, F. R. (2007). Trypanosoma cruzi strains, Tulahuen 2 and $\mathrm{Y}$, besides the difference in resistance to oxidative stress, display differential glucose-6-phosphate and 6- Phosphogluconate dehydrogenases activities. Acta Tropica 101, 54-60.

Nogueira, N. P., Saraiva, F. M. S., Sultano, P. E., Cunha, P. R. B. B. Laranja, G. A. T., Justo, G. A., Sabino, K. C. C., Coelho, M. G. P., Rossini, A., Atella, G. C. and Paes, M. C. (2015). Proliferation and differentiation of Trypanosoma cruzi inside its vector have a new trigger: redox status. PLoS ONE 10, e0116712.

Paiva, C. N. and Bozza, M. T. (2014). Are reactive oxygen species always detrimental to pathogens? Antioxidants \& Redox Signaling 20, 1001-1012. Paiva, C. N., Feijó, D. F., Dutra, F. F., Carneiro, V. C., Freitas, G. B., Alves, L. S., Mesquita, J., Fortes, G. B., Figueiredo, R. T., Souza, H. S. P., Fantappié, M. R., Lannes-Vieira, J. and Bozza, M. T. (2012). Oxidative stress fuels Trypanosoma cruzi infection in mice. Fournal of Clinical Investigation 122, 2531-2542.

Peloso, E. F., Vitor, S. C., Ribeiro, L. H., Piñeyro, M. D., Robello, C. and Gadelha, F. R. (2011). Role of Trypanosoma cruzi peroxiredoxins in mitochondrial bioenergetics. Fournal of Bioenergetics and Biomembranes $\mathbf{4 3}$, 419-424.

Peloso, E. F., Gonçalves, C. C., Silva, T. M., Ribeiro, L. H., Piñeyro, M. D., Robello, C. and Gadelha, F. R. (2012). Tryparedoxin peroxidases and superoxide dismutases expression as well as ROS release are related to Trypanosoma cruzi epimastigotes growth phases. Archives of Biochemistry and Biophysics 520, 117-122.

Pfaffl, M. W. (2001). A new mathematical model for relative quantification in real-time RT-PCR. Nucleic Acids Research 29, 2002-2007.

Piacenza, L., Peluffo, G., Alvarez, M. N., Kelly, J. M., Wilkinson, S. R. and Radi, R. (2008). Peroxiredoxins play a major role in protecting Trypanosoma cruzi against macrophage- and endogenously-derived peroxynitrite. Biochemical Fournal, 410, 359-368.

Piacenza, L., Alvarez, M. N., Peluffo, G. and Radi, R. (2009a) Fighting the oxidative assault: the Trypanosoma cruzi journey to infection. Current Opinion in Microbiology 12, 415-421.

Piacenza, L., Zago, M. P., Peluffo, G., Alvarez, M. N., Basombrio, M. A. and Radi, R. (2009b). Enzymes of the antioxidant network as novel determiners of Trypanosoma cruzi virulence. International fournal for Parasitology 39, 1455-1464.

Piacenza, L., Peluffo, G., Alvarez, M. N., Martínez, A. and Radi, R. (2013). Trypanosoma cruzi antioxidant enzymes as virulence factors in Chagas disease. Antioxidants \& Redox Signaling 19, 723-734.

Piñeyro, M. D., Parodi-Talice, A., Arcari, T. and Robello, C. (2008). Peroxiredoxins from Trypanosoma cruzi: virulence factors and drug targets for treatment of Chagas disease? Gene 408, 45-50.

Räz, B., Iten, M., Grether-Bühler, Y., Kaminsky, R. and Brun, R. (1997). The Alamar Blue assay to determine drug sensitivity of African trypanosomes (T.b. rhodesiense and T.b. gambiense) in vitro. Acta Tropica $\mathbf{6 8}$, $139-147$.
Romão, P. R., Fonseca, S. G., Hothersall, J. S., Noronha-Dutra, A. A. Ferreira, S. H. and Cunha, F. Q. (1999). Glutathione protects macrophages and Leishmania major against nitric oxide-mediated cytotoxicity. Parasitology 118, 559-566.

Romero, I. C., Saraiva, N. and Walker, J. (2005). Selective action of fluoroquinolones against intracellular amastigotes of Leishmania (Viannia) panamensis in vitro. Fournal of Parasitology 91, 1474-1479.

Romero, I., Téllez, J., Yamanaka, L. E., Steindel, M., Romanha, A. J. and Grisard, E. C. (2014). Transsulfuration is an active pathway for cysteine biosynthesis in Trypanosoma rangeli. Parasites $\Xi^{\circ}$ Vectors 7, 197.

Rossato, F. A., Zecchin, K. G., La Guardia, P. G., Ortega, R. M., Alberici, L. C., Costa, R. A. P., Catharino, R. R., Graner, E., Castilho, R. F. and Vercesi, A. E. (2014). Fatty acid synthase inhibitors induce apoptosis in non tumorigenic melan-a cells associated with inhibition of mitochondrial respiration. PLoS ONE 9, e101060.

Sambrook, J., Fritch, E. F. and Maniatis, T. (2001). Molecular Cloning A Laboratory Manual, Vol. 3, 2nd Edn. Cold Spring Harbor, New York, USA

Schwende, H., Fitzke, E., Ambs, P. and Dieter, P. (1996). Differences in the state of differentiation of THP-1 cells induced by phorbol ester and 1,25-dihydroxyvitamin D3. Fournal of Leukocyte Biology 59, 555-561.

Shames, S. L., Fairlamb, A. H., Cerami, A. and Walsh, C. T. (1986). Purification and characterization of trypanothione reductase from Crithidia fasciculata newly discovered member of the family of disulphide containing flavoprotein oxidoreductase. Biochemical 25, 3519-3526.

Silva, M., Peloso, E. F., Vitor, S. C., Ribeiro, L. H. and Gadelha, F. R. (2011). $\mathrm{O}_{2}$ consumption rates along the growth curve: new insights into Trypanosoma cruzi mitochondrial respiratory chain. Fournal of Bioenergetics and Biomembranes 43, 409-417.

Stoco, P. H., Wagner, G., Talavera-Lopez, C., Gerber, A., Zaha, A., Thompson, C. E., Bartholomeu, D. C., Lückemeyer, D. D., Bahia, D., Loreto, E., Prestes, E. B., Lima, F. M., RodriguesLuiz, G., Vallejo, G. A., Filho, J. F., Schenkman, S., Monteiro, K. M., Tyler, K. M., de Almeida, L. G., Ortiz, M. F., Chiurillo, M. A., de Moraes, M. H., de Cunha, O. L., Mendonça-Neto, R., Silva, R., Teixeira, S. M., Murta, S. M., Sincero, T. C., Mendes, T. A., Urmenyi, T. P., Silva, V. G., DaRocha, W. D., Andersson, B., Romanha, A. J., Steindel, M., de Vasconcelos, A. T. and Grisard, E. C. (2014). Genome of the avirulent human-infective Trypanosome - Trypanosoma rangeli. PLOS Neglected Tropical Diseases 8, e3176.

Souza, A. V. G., Petretski, J. H., Demasi, M., Bechara, E. J. H. and Oliveira, P. L. (1997). Urate protects a blood-sucking insect against hemin-induced oxidative stress. Free Radical Biology \& Medicine 22, 209-214.

Taylor, M. C., Kelly, J. M., Champman, C. J., Fairlamb, A. H. and Miles, M. A. (1994). The structure, organization, and expression of the Leishmania donovani gene encoding trypanothione reductase. Molecular and Biochemical Parasitology 64, 293-301.

Teixeira, S. M. R. and Darocha, W. D. (2003). Control of gene expression and genetic manipulation in the Trypanosomatidae. Genetics and Molecular Research 2, 148-158.

Temperton, N. J., Wilkinson, S. R., Meyer, D. J. and Kelly, J. M. (1998). Overexpression of superoxide dismutase in Trypanosoma cruzi results in increased sensitivity to the trypanocidal agents gentian violet and benznidazole. Molecular and Biochemical Parasitology 96, $167-176$.

Tovar, J. and Fairlamb, A. H. (1996). Extrachromosomal, homologous expression of trypanothione reductase and its complementary mRNA in Trypanosoma cruzi. Nucleic Acids Research 24, 2942-2949.

Tovar, J., Cunningham, M. L., Smith, A. C., Croft, S. L. and Fairlamb, A. H. (1998). Downregulation of Leishmania donovani trypanothione reductase by heterologous expression of a trans-dominant mutant homologue: effect on parasite intracellular survival. Proceedings of the National Academy of Sciences 95, 5311-5316.

Wang, H. and Joseph, J. A. (1999). Quantifying cellular oxidative stress by dichlorofluorescein assay using microplate reader. Free Radical Biology \& Medicine 27, 612-616. 